\title{
Illustrations of serial mediation using PROCESS, Mplus and R 0 (1)
}

\author{
Laura Lemardelet $^{\mathrm{a} \otimes}$ (๑) and Pier-Olivier Caron ${ }^{\mathrm{b}} \odot$ \\ ${ }^{a}$ Faculté des Sciences de l’Éducation, Université Laval \\ ${ }^{\mathrm{b}}$ Université TÉLUQ
}

\begin{abstract}
There has been an increased interest among researchers in the behavorial and social sciences for mediation models. This interest is well deserved: mediation can explain via intermediate variables the relationship between an independent variable and a dependent variable. Many software programs are now available to perform such analysis. However, there is a lack of articles to guide users to perform more complex models. The purpose of the current manuscript is to provide a tutorial on serial mediation analysis using software requiring less programming skills like SPSS (PROCESS), and Mplus to more advanced software such as R. In this manuscript, we first introduce the simple mediation analysis. Second, we explain the different parameters and effects of a serial mediation analysis with two mediators. Third, we show how to generate data using R. Fourth, we explain the input and output of PROCESS, Mplus, and R. Finally, a practical example is performed with Mplus.
\end{abstract}

Keywords $₫$ mediation, serial mediation. Tools $\backsim$ PROCESS, Mplus, R.

Acting Editor $\because$ Denis Cousineau (Université d'Ottawa)

\section{laura.lemardelet.1@ulaval.ca}

10.20982/tqmp.18.1.p066

\section{Introduction}

There has been an increasing trend in the behavioral, social, and educational sciences, among others, to unravel the mechanisms through which one variable influence another (MacKinnon, Fairchild, \& Fritz, 2007; Preacher, 2015). Mediation analysis is the privileged statistical analysis model to uncover the relation between two variables (a predictor and an outcome) attributed to a third intermediatory variable (the mediator). The wide availability of software, such as PROCESS (Hayes, 2017), Mplus (Muthén \& Muthén, 2017), and R (R Core Team, 2021), facilitates its spread among researchers. Despite widespread use, there is a lack of pedagogical articles to guide students and researchers through more complex mediation models, such as serial mediation.

The purpose of the current manuscript is to provide a tutorial on serial mediation analysis for researchers and students in social and behavioral sciences. In this manuscript, we focus on three methods to implement serial mediation as to build on more user-friendly software (SPSS, Mplus) to reach to more technical methods. The sec- tions of the manuscript are as follow: the theoretical foundations of simple and serial mediation are described, an illustrative example to generate data for serial mediation is presented, mediation analysis with PROCESS, Mplus and $\mathrm{R}$ is explained, and finally, a practical example is provided with Mplus.

\section{Simple mediation}

Simple mediation is the most well-known and prototypical mediation model. It describes the relationship between an independent variable $(x)$ and a dependent variable $(y)$ by adding a third variable called the mediator $(m)$. Methodologically, for all mediation models, a temporal difference between the independent variable (IV; time 1), the mediator variable (MV; time 2) and the dependent variable (DV; time 3) is recommended because cross-sectional models provide biased estimates by omitting the prior values of these variables and the effects of the variables on themselves (Gollob \& Reichardt, 1987). Thus, longitudinal models provide better inferences about causal relationships within a mediation model (Cole \& Maxwell, 2003).

To illustrate the mediation model, Figure 1 is depicted 
Figure 1 - Illustration of models. (a) Illustration of the total effect between an independent variable, $x$, and a dependent variable, $y$. (b) Illustration of a mediated relation between an independent variable, $x$, to a dependent variable, $y$, through a mediator, $m$.

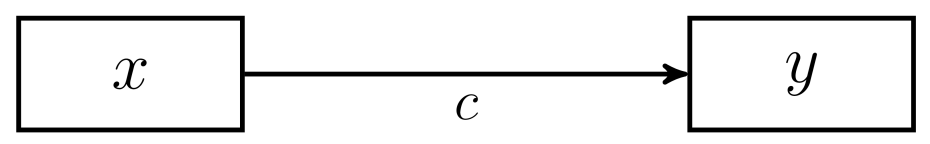

a) Total effect

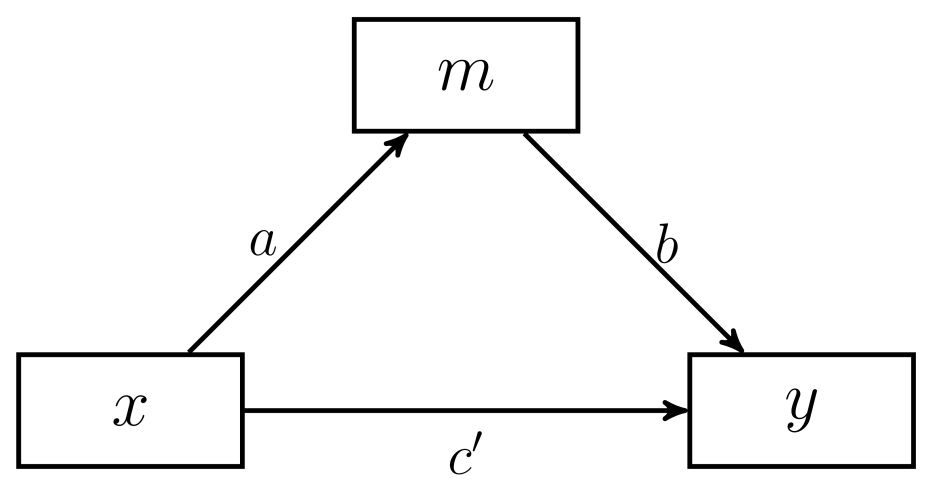

b) Indirect effect

into two parts: a bivariate regression model and a mediation model. Figure 1a shows the relationship between $x$ and $y$ without accounting for the mediator $(m)$, which is called the total effect, represented using the parameter $c$. Adding a mediator between $x$ and $y$ yield the path diagram in Figure $1 \mathrm{~b}$. Here, the parameter $a$ is the regression of $x$ on $m$. The parameter $b$ is the regression of $m$ on $y$ accounting for $x$. The parameter $c^{\prime}$ is the regression of $x$ on $y$ accounting for $m$. All parameters are regression coefficients. Three simple effects can be identified:

1. The total effect of $x$ on $y(c)$;

2. The simple effect of $x$ on $m(a)$;

3. The simple effect of $m$ on $y$ controlling for $x(b)$.

By adding the mediator, the path diagram includes an indirect effect which is the mediating effect of $m$ between $x$ and $y$, e.g., the product of paths $a$ and $b$. If the indirect effect is statistically significant, then $m$ is deemed a mediator.

To determine the significance of the indirect effect, the bootstrap method is privileged by methodological researchers. The bootstrap method (Efron \& Tibshriani, 1994) is a computer-intensive method which use random resampling to estimate the sampling distribution of almost any statistics. In a mediation analysis, subjects from the original sample are randomly selected, with replacement, to generate many subsamples, allowing the computation of the two parameters of interest which are $a$ and $b$. Obtaining these two parameters will allow to obtain their product and to calculate the indirect effect of mediation. The calculation of the indirect effect by boostrapping will allow the estimation of the confidence intervals and the standard errors of the desired effect. This method is recommended over other methods because it follows the empirical distribution of the indirect effect (non-normal) resulting in greater statistical power (Caron \& Valois, 2018; Özdil \& Kutlu, 2019), more appropriate Type I error rate (Caron, 2019), and robustness when the data are not normal (Cheung \& Lau, 2008).

In this manuscript, we will not go deeper on simple mediation as it has been already addressed by other articles (Caron \& Valois, 2018; Fairchild \& McDaniel, 2017; Kane \& Ashbaugh, 2017; Lange, Hansen, Sørensen, \& Galatius, 2017), we focus now on serial mediation. 
Figure 2 - Illustration of serial mediation analysis with two mediators.

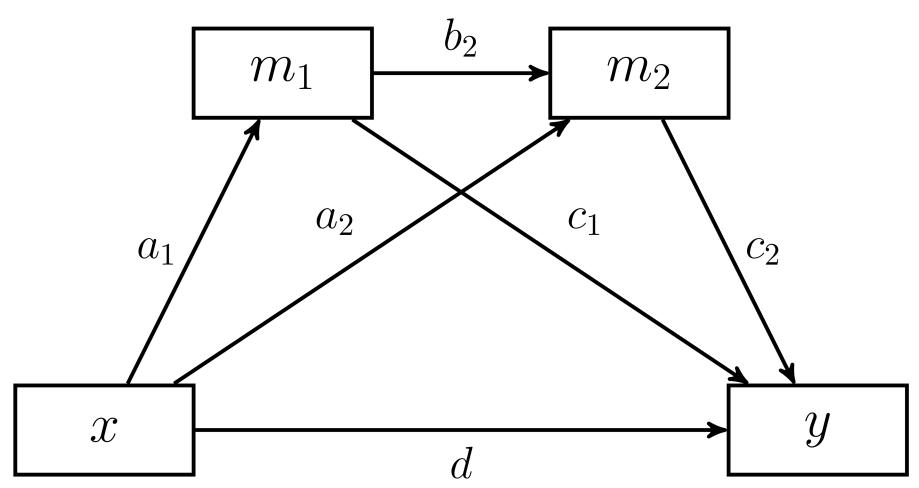

$(e)$

\section{Serial mediation}

Human behavior is rarely simple. There is a plethora of ongoing processes which can be accounted by models ranging from not so complicated to very convoluted. One way to account for complex human behavior is the addition of multiple mediators, such as parallel mediation or serial mediation. In parallel mediation, at least two mediating variables are non-consecutive in times whereas at least two variables are consecutive in serial mediation. Figure 2 depicts a serial mediation model including two mediators $m_{1}$ and $m_{2}$. The serial mediation includes many parameters:

- Path $a_{1}$ is the regression of $x$ on $m_{1}$;

- Path $a_{2}$ is the regression of $x$ on $m_{2}$;

- Path $b_{2}$ is the regression of $m_{1}$ on $m_{2}$ controlling for the effects of $x$;

- Path $c_{1}$ is the regression of $m_{1}$ on $y$ controlling for the effects of $x$;

- Path $c_{2}$ is the regression of $m_{2}$ on $y$ by controlling for the effects of $x$ and $m_{1}$;

- Path $e$ is the total effect, that is, the regression of $x$ on $y$;

- Path $d$ is the direct effect which is the effect of $x$ on $y$ by controlling for the effects of $m_{1}$ and $m_{2}$.

To estimate these parameters, three regressions are necessary to perform a serial mediation analysis and to compute the indirect effect. The first step is to regress $x$ to $m_{1}$ to obtain the parameter $a_{1}$. The second is to regress $x$ and $m_{1}$ to $m_{2}$ to obtain $a_{2}$ and $b_{2}$ respectively. The third step is to regress $x, m_{1}$ and $m_{2}$ to $y$ to obtain $d, c_{1}$ and $c_{2}$, respectively. A fourth optional step is to regress $x$ on $y$, to obtain $e$, the total effect, which can also be computed from the sum of all primary indirect effects $\left(a_{1} c_{1}, a_{2} c_{2}, a_{1} b_{2} c_{2}\right)$ and the total effect; $e=d+a_{1} c_{1}+a_{2} c_{2}+a_{1} b_{2} c_{2}$. The struc- tural equation model has the advantage of running all regressions simultaneously and to yield fit indices when the model is not saturated.

When two mediators are considered, the total effect, $e$ is divided into five indirect effects. There are three primary indirect effects:

- the specific indirect effect of $m_{1}$, the product $a_{1} c_{1}$, shown in Figure 3a;

- the specific indirect effect of $m_{2}$, the product $a_{2} c_{2}$; shown in Figure 3b;

- the serial indirect effect of $m_{1}$ and $m_{2}$, the product $a_{1} b_{2} c_{2}$, shown in Figure 3e;

and two secondary indirect effects:

- the specific indirect effect of $m_{1}$, the product $a_{1} b_{2}$, shown in Figure 3d;

- the specific indirect effect of $m_{2}$, the product $b_{2} c_{2}$, shown in Figure 3c.

The three primary indirect effects are effects that goes from $x$ (the exogenous variable) to $y$ (the outcome). The two secondary effects concern the relationship from $x$ to $m_{2}\left(a_{1} b_{2}\right)$ or from $m_{1}$ to $y\left(b_{2} c_{2}\right)$. Secondary effects are rarely reported in the output but can be of interest, especially if the intermediary path between the two mediators is not significant.

Primary indirect effects are grouped under the total indirect effect. If this effect is significantly different from zero, then there is at least one mediation effect in the model. First, we have to look if the serial indirect effect, $a_{1} b_{2} c_{2}$ is significantly different from zero which suggests a serial mediation effect. Second, if it is not significant, other indirect effects should be investigated. The absence of significant relation between $m_{1}$ and $m_{2}$ could suggest a parallel mediation or, otherwise, a simple indirect effect from a single mediator. 
Figure 3 - The five indirect effects included in a serial mediation analysis with two mediators.

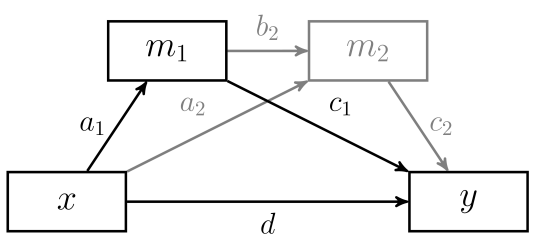

a) The primary indirect effect of $m_{1}, a_{1} c_{1}$

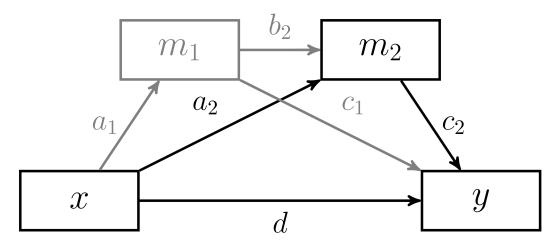

b) The primary indirect effect of $m_{2}, a_{2} c_{2}$

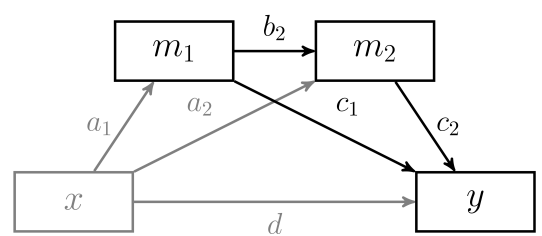

c) The secondary indirect effect of $m_{2}, b_{2} c_{2}$

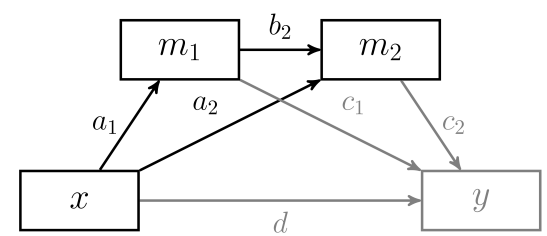

d) The secondary indirect effect of $m_{1}, a_{1} b_{2}$

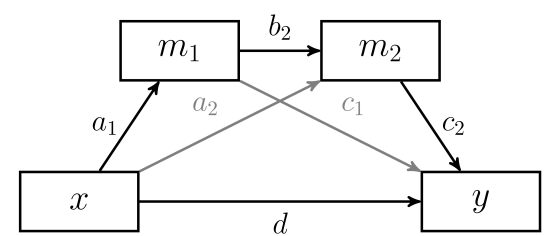

e) The primary indirect effect of $m_{1}$ and $m_{2}, a_{1} b_{2} c_{2}$

\section{Illustrative example}

To illustrate serial mediation analysis, data were generated with R (R Core Team, 2021) using codes inspired from Caron and Valois (2018). For the sake of simplicity, variables $x, m_{1}, m_{2}$ and $y$ have a normal distribution, with a mean of 0 and a standard deviation of 1 . This led population parameters to be standardized coefficients. Listing 1 shows the R code to generate the model data with $n=432$, and parameters: $a_{1}=.5, a_{2}=.3, b_{2}=.2, c_{1}=.7, c_{2}$ $=.4$, and $d=0$. In this function, the first step is to calculate the errors (variance of the residuals) from $m_{1}, m_{2}$ and $y: \varepsilon_{m_{1}}, \varepsilon_{m_{2}}$, and $\varepsilon_{y}$. Each formula is identified by the lines of $\mathrm{R}$ syntax given in Listing 1 . The following are the three formulas for the variance of the three residuals errors, $\varepsilon_{m_{1}}, \varepsilon_{m_{2}}$ and $\varepsilon_{y}$ :

$$
\begin{gathered}
\operatorname{var}\left(\varepsilon_{m_{1}}\right)=1-a_{1}^{2} \\
\operatorname{var}\left(\varepsilon_{m_{2}}\right)=1-a_{2}^{2}+b_{2}^{2}+2 a_{2} b_{2} a_{1} \\
\operatorname{var}\left(\varepsilon_{y}\right)=1-\left(d^{2}+c_{1}^{2}+c_{2}^{2}+2 d c_{1} a_{1}+\right. \\
2 d c_{2}\left(a_{2}+a_{1} b_{2}\right)+ \\
\left.2 c_{1} c_{2}\left(b_{2}+a_{1} a_{2}\right)\right)
\end{gathered}
$$

(line 5)

(line 6)

(line 7)

To achieve a standardized scenario, the explained variance of predictors is subtracted from 1 (the variance of outcome which is set to 1; Caron \& Lemardelet, 2021). The variable $x$ is generated (line 11) using a standard normal distribution for $X$ so that $X \sim \mathcal{N}(0,1)$ must be generated, to obtain the data for $m_{1}, m_{2}$ and $y$. For the computation of $m_{1}, m_{2}$ and $y$ data, the errors are normally distributed with mean 0 and standard deviations $s d\left(\varepsilon_{m_{1}}\right), s d\left(\varepsilon_{m_{2}}\right)$, and $\operatorname{sd}\left(\varepsilon_{y}\right)$. When $x$ is generated, it is possible to obtain the data from $m_{1}$, which is the first regression of the serial mediation model. The mathematical formula is as follows:

$$
m_{1}=a_{1} x+\varepsilon_{m_{1}}
$$

(line 12)

When $m_{1}$ is created, the second regression of the mediation analysis, $m_{2}$, can be computed:

$$
m_{2}=a_{2} x+b_{2} m_{1}+\varepsilon_{m_{2}}
$$

(line 13)

Finally, having obtained the data for $x, m_{1}$ and $m_{2}$, we can calculate $y$, which is the last regression of the model:

$$
y=d x+c_{1} m_{1}+c_{2} m_{2}+\varepsilon_{y}
$$

(line 14)

An optional step could be to calculate the parameter $e$ which represents the total effect of $x$ on $y$ :

$$
e=d+a_{1} c_{1}+a_{2} c_{2}+a_{1} b_{2} c_{2}
$$

(line 17)

The data were generated with the default parameters $\left(a_{1}=.5, a_{2}=.3, b_{2}=.2, c_{1}=.7, c_{2}=.4, d=0\right.$ ) with the default sample size $n=432$ (a sample size appropriate for serial mediation analyses). See supplementary material on the journal's web site for the data file. The data set was then used to perform the analyses with the PROCESS macro of SPSS, Mplus and R.

\section{Analysis in Process}

IBM SPSS (IBM Corporation, 2020) is probably the most known and used statistical software in the behavioral science. However, it is not optimized for mediation analysis because it does not allow to run simultaneous several 
Figure 4 - Main dialog box in PROCESS and dialogue box for options.

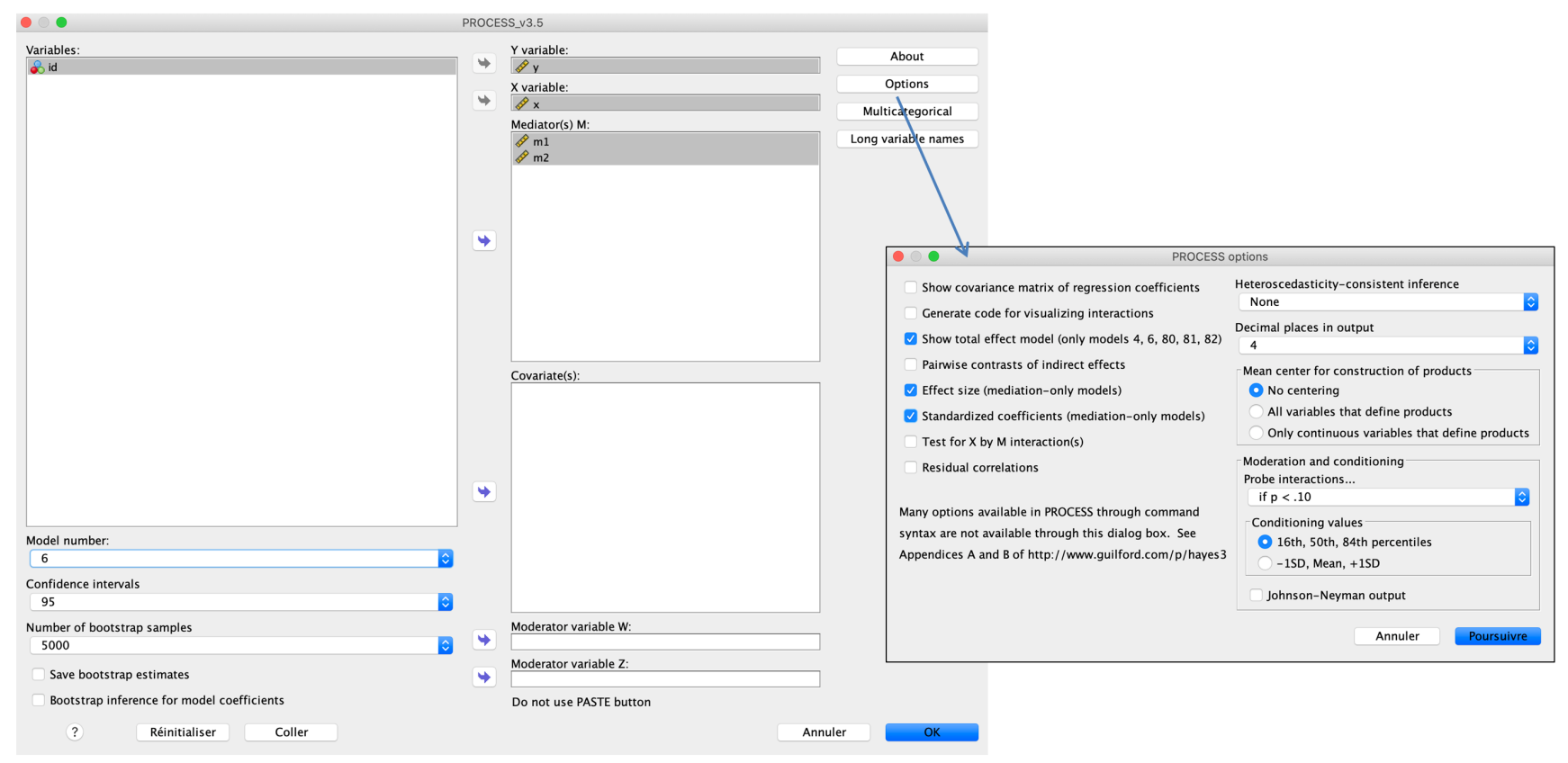

linear regressions, which implies that indirect effects and their bootstraping cannot be performed. By adding PROCESS (Hayes, 2017), an SPSS macro that has to be installed by the users, both mediation and moderation analyses can be performed. PROCESS is an add-on, easily and freely available at the following URL: https://www.processmacro. org/download.html. The installation guidelines and the various possible models (more than 75 models) are included in the downloaded file. The input (dialog box) and the output will be presented to understand the serial mediation analysis with PROCESS.

\section{Input}

Once installed, we can select PROCESS in the SPSS dialog boxes (analyze $\rightarrow$ regression). Figure 4 shows the main dialog box to customize the serial mediation model. First, we have to specify the desired model in model number. For serial mediation with two mediators, this is model number 6 (refer to the document provided with PROCESS for an overview of all possible models). Second, the variables of the model are selected in the left section of the dialog box. Finally, we have to specify the confidence interval and the number of resamples we want. By default, SPSS uses a confidence interval of 95\% and bootstrap of 5000 replication. Now we have to click on opt i ons to enter the required parameters.

After clicking on options, a new dialog box opens, as shown inset Figure 4. Here PROCESS indicates the optional information for the analysis. We recommend three relevant options: show total effect model, effect size and standardized coefficients.

Once options are chosen, we click on Cont inue and we can carry the analysis by clicking on OK.

\section{Output}

Appendix A shows the PROCESS output. For an easier interpretation of the results, lines were assigned for all items present in the output file. In addition, yellow allows for quick identification of important results to be located in Appendix A (the output of the SPSS macro analysis). Parameter $a_{1}$ is shown at line $33(\beta=.49$ [.410; .576], $p<.001$; hereafter, numbers between brackets denote 95\% confidence interval), parameter $a_{2}$ is shown at line 51 ( $\beta=.18$ [.090; .265], $p<.001$ ), parameter $b_{2}$ is shown at line 52 ( $\beta=.46$ [.365; .539], $p<.001)$, parameter $c_{1}$ is shown at line 72 ( $\beta=-.02$ [-.087; .056], $p=.668$ ), the parameter $c_{2}$ is at line 73 ( $\beta=.67$ [.593; .734], $p<.001$ ), the direct effect $d$ is at line 71 ( $\beta=.25$ [-.093; .019], $p<.001$ ), the total effect $e$ is at line 90 ( $\beta=.52$ [.425; .583], $p<.001$ ), and line 118 shows the total indirect effects ( $\beta=.27$ [.210; .318]) which is significant because zero is not included in the confidence interval. The indirect effect, $a_{1} b_{2} c_{2}$ (line 121), shown in Figure 3e, is deemed significant ( $\beta=.15$ [.113; .193]). Likely, there is a serial mediation effect with 
Table 1 a Results produced by the package pathanalysis with R.

\begin{tabular}{|c|c|c|c|c|c|}
\hline & Estimate & S.E. & CI Lower $95 \%$ & CI Upper 95 \% & $p$-value \\
\hline $\mathrm{x}->\mathrm{m} 1$ & 0.492 & 0.043 & 0.409 & 0.580 & 0.000 \\
\hline $\mathrm{x}->\mathrm{m} 2$ & 0.181 & 0.040 & 0.105 & 0.262 & 0.000 \\
\hline$x->y$ & 0.252 & 0.035 & 0.184 & 0.318 & 0.000 \\
\hline $\mathrm{m} 1$-> m2 & 0.464 & 0.043 & 0.379 & 0.546 & 0.000 \\
\hline $\mathrm{m} 1->\mathrm{y}$ & -0.016 & 0.038 & -0.091 & 0.059 & 0.674 \\
\hline$m 2->y$ & 0.666 & 0.039 & 0.589 & 0.744 & 0.000 \\
\hline $\mathrm{x}->\mathrm{m} 1->\mathrm{m} 2$ & 0.228 & 0.029 & 0.172 & 0.288 & 0.000 \\
\hline $\mathrm{x}->\mathrm{m} 1 \mathrm{->} \mathrm{y}$ & -0.008 & 0.019 & -0.046 & 0.029 & 0.675 \\
\hline$x->m 2->y$ & 0.121 & 0.028 & 0.068 & 0.177 & 0.000 \\
\hline $\mathrm{m} 1->\mathrm{m} 2->\mathrm{y}$ & 0.309 & 0.035 & 0.242 & 0.378 & 0.000 \\
\hline$x \rightarrow m 1->m 2->y$ & 0.152 & 0.022 & 0.111 & 0.197 & 0.000 \\
\hline total indirect & 0.265 & 0.033 & 0.202 & 0.331 & 0.000 \\
\hline total effect & 0.517 & 0.041 & 0.438 & 0.597 & 0.000 \\
\hline
\end{tabular}

the mediators $m_{1}$ and $m_{2}$. As for the two others primary indirect effects: the indirect effect $a_{1} c_{1}$ (Figure 3a) shown to be non-significant [-.046; .028] at line 119, which imply there is no mediated effect passing through $m_{1}$ and the indirect effect $a_{2} c_{2}$ (Figure 3b) emerges as significant [.068; .174 ] at line $\mathbf{1 2 0}$, so there is a mediation effect when passing through $m_{2}$. PROCESS does not provide the secondary indirect effects.

\section{Analysis in Mplus}

Mplus (Muthén \& Muthén, 2017) is a statistical modelling program that provides researchers with a flexible tool to analyze complex statistical models. Its programming is at the halfway between SPSS and R. Mplus is exclusively based on a syntax, unlike SPSS, but the syntax is easier than R. In this manuscript, the basic principles of the syntax of Mplus will not be discussed (for a detail presentation see Byrne, 2013; Caron, 2018; Geiser, 2013; Kelloway, 2015; Wang \& Wang, 2020), we will focus on the commands needed to run a serial mediation analysis and on understanding the output file.

\section{Input}

For all analyses in Mplus (version 8.3), shown in listing 2, it is necessary to enter the title (line 1), the location of the data (line 3), the name of the variables in the file (line 6) and the name of the variables to use (line 7). As a reminder, each command in Mplus must end with the following punctuation " ; ". To carry out the serial mediation analysis, we have to specify first the bootstrap and the number of bootstraps under ANALYSIS (line 10). Here, 5000 bootstrap samples are required. Second, lines 13 to 15 specify the mediation model. Line $\mathbf{1 3}$ is the path between $x$ and $m_{1}$, line 14 is the relationship between $m_{1}$ and $m_{2}$ accounting for $x$ and line $\mathbf{1 5}$ is the relationship between $x$ and $y$ through $m_{1}$ and $m_{2}$. Third, the indirect model is specified between the variables $x$ and $y$ (line 18). Finally, line 20 allows us to obtain the standardized coefficients and the confidence intervals from the Bootstrap. Now the serial mediation analysis can be performed.

\section{Output}

Appendix B is the output file of the serial mediation analysis with Mplus. Like previously, we kept the same presentation style (the lines and yellow color for the parameters). All the estimates are the same; the only differences are with regards to the bootstrap intervals which differs on the second decimals. Such small differences are to be expected as these bootstrap intervals are based on 5000 random subsamples. From line 236 to line 250, the standardized results with Bootstrap are available and from line 291 to line 320, these are the indirect, direct, and total standardized effects with bootstrapping. Line 241 is the parameter $a_{1}(\beta=.49[.417 ; .560])$. Line 244 is the parameter $a_{2}(\beta=.18[.101 ; .256])$. Line 245 is the parameter $b_{2}(\beta=.46[.386 ; .542])$. Line 249 is the parameter $c_{1}(\beta=-.02[-.092 ; .056])$. Line 250 is the parameter $c_{2}$ $(\beta=.67[.604 ; .727])$. The direct effect, $d$, is on the line 248 and 320 ( $\beta=.25[.183 ; .320])$. Total effect, $e$, is on the line 299 ( $\beta=.52[.445 ; .581])$ and line 300 shows the total indirect effects ( $\beta=.27$ [.209; .321]). For primary indirect effects, the line 305 shows the indirect effect $a_{1} c_{1}$ that is insignificant ( $\beta=-.01[-.047 ; .027])$, the line 310 shows the indirect effect $a_{2} c_{2}$ that is significant ( $\beta=.12$ [.068; .172]) and the line 316 shows the indirect effect $a_{1} b_{2} c_{2}$ that is significant ( $\beta=.15$ [.116; .196]). Unlike Process, Mplus provides $\mathrm{p}$-values for indirect effects. However, as for Process, Mplus does not provide the secondary indirect effects. 


\section{Analysis in R}

$\mathrm{R}$ is a free programming software for statistical computing and graphics (R Core Team, 2021). It is often use in conjunction with RStudio, an integrated development environment (Team, 2020), which increases the convenience and accessibility of R. Alone, R cannot carry out mediation analyses. However, being a collaborative platform, there are already available package that can be downloaded (install.packages ()). Packages for mediation analysis are mediation (Tingley, Yamamoto, Hirose, Keele, \& Imai, 2014) and Rmediation (Tofighi \& Mackinnon, 2011), both coming with its own documentation. The existence of packages should not overshadow the fact that it can be quite easy to develop its own script to perform hypothesis testing of indirect effects with some basic programming skills. Herein, we will describe our own script of bootstrap for indirect effect, which is inspired from Caron and Valois (2018).

\section{Bootstrap method}

The bootstrap method (Efron \& Tibshriani, 1994) is a computer-intensive method which use random resampling to estimate the sampling distribution of almost any statistics. Its very basic is to randomly select with replacement subjects of the original sample to generate many subsamples and then computing the statistics of interest. Confidence intervals can be computed from the sampling distribution, which can then be used to guide statistical inference.

Listing 3 shows an example of code that can be used to assess the significance of indirect effect in mediation analysis. The code is separated in four main parts: the code to 1) carry a specific indirect effect; 2) use the bootstrap method; 3) run the analysis for a specific indirect effect; 4) the importation of package to carry a complete mediation analysis. One can easily use the code herein (complete code in supplementary file available).

The lines 1 to 9 specify a function to compute a desired statistic, herein the indirect effect of $x$ through $m_{1}$ and $m_{2}$ to the outcome $y$. The function is called indirect ( ) and is used within the bootstrap method after. The function extracts the relevant regression estimates to compute the indirect effect and carry their product. It then returns the results. If another indirect effect was of interest, another function should be written to compute this new one. A general case will be describe using a homemade package.

The lines 11 to 26 is a homemade function to carry the bootstrap method called boot ( ). It works for any statistics specified as the argument stat, like the median for instances, not just indirect ( ). The core of the bootstraps is found in lines 18-21 where the function sample () (line
19) randomly selects with replacement the participants among the $n$ participants (recorded at line 15). The next line (line 20) computes the desired statistics and records it iteratively in the variable est. Lines 19 and 20 are looped nrep times. Once the resample is finished, the bootstrap samples are used to compute an average estimate, its standard error and its confidence interval. The boot () function returns the results. The number of replications and the type I error rate can be specified by the user (by default nrep $=5000$; alpha $=.05$ ).

Lines 28-32 shows how to use boot() and indirect ( ) together. At line 30, the data set is imported in R. At line 32, the boot ( ) function is used with the desired statistics, which is indirect ( ), and the given data set. Its output returns the estimate, its standard error and its confidence interval, which can then be interpreted.

A homemade package, called pathanalysis, is in development by the second author (Caron, 2021). The package can be downloaded from GitHub directly into R. The code to do so are presented in the fourth part of the code at lines 34-47. At first, the package devtools (or remotes) must be installed, which can be easily done with line 37. Once installed, line 39 imports the package from GitHub and using line $\mathbf{4 0}$ makes the package available in the environment. The package contains the data sets use in this example and so can be imported via lines 41-42. The package contains the function mediation (). This function needs as an argument the model, that is, the order of the variables in the mediation, outcome to first variable, and a data set. The argument model is a formula like $y$ $\sim \mathrm{m} \sim \mathrm{x}$ which identify the outcome and first variables and all mediator in between. The $\sim$ acts in a similar fashion like other formula in $\mathrm{R}$ (such as $\operatorname{lm}($ ), for instances), it specifies the dependent variable on the left and their independent variables on the right (like the $\mathrm{ON}$ function in Mplus). Here, the model is model $=\mathrm{y} \sim \mathrm{m} 2 \sim \mathrm{m} 1 \sim$ $x$. The function mediation ( ) returns all indirect effects in the model, which is carried out at lines 46-47.

\section{Output}

Table 1 is the output file of the serial mediation analysis with package pat hanalys is with R. Line 1 is the parameter $a_{1}(\beta=.49,[.409 ; .580] p<.001)$. Line 2 is the parameter $a_{2}(\beta=.18,[.105 ; .262] p<.001)$. Line 4 is the parameter $b_{2}(\beta=.46[.379 ; .546] p<.001)$. Line 5 is the parameter $c_{1}(\beta=-.02,[-, 091 ; .059] p=.674)$. Line 6 is the parameter $c_{2}(\beta=.67,[.589 ; .744] p<.001)$. The direct effect, $d$, is on the line 3 ( $\beta=.25$, [184; .318] $p<.001)$. Total effect, $e$, is on the line 13 ( $\beta=.52$, [.438; .597] $p<.001)$ and line 12 shows the total indirect effects $(\beta=.27$ [.202; .331] $p<.001$ ). Unlike Process and Mplus, $\mathrm{R}$ provides $\mathrm{p}$ values for indirect effects. For primary indirect effects, the 
Figure 5 - (Left) The theoretical model of the mediating effects of self-esteem and loneliness between victimization and depression; (right) the fitted model.

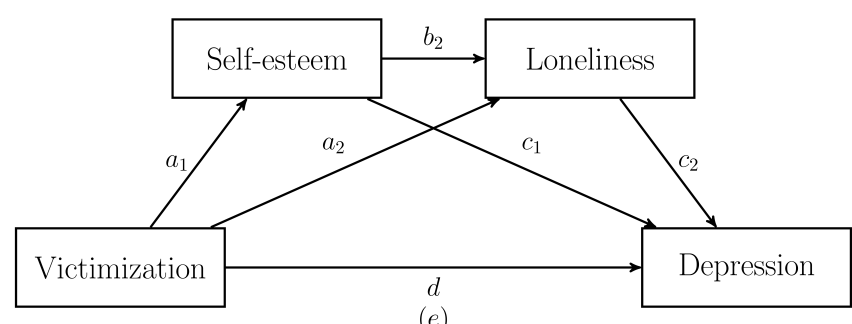

(e)

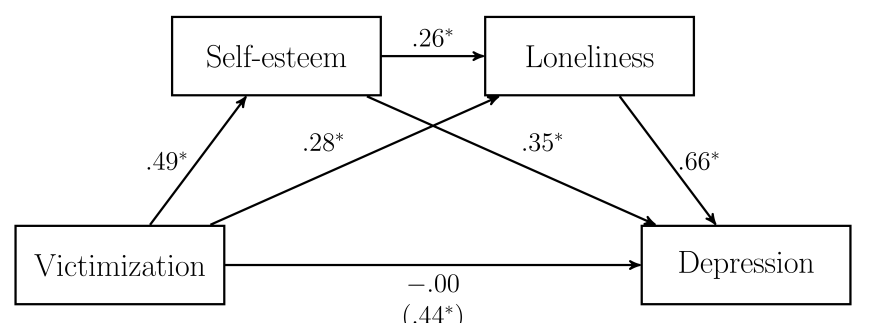

$\left(.44^{*}\right)$ line 8 shows the indirect effect $a_{2} c_{1}$ that is insignificant ( $\beta=-.01[-.046 ; .029], p=.675$ ), the line 9 shows the indirect effect $a_{2} c_{2}$ that is significant ( $\beta=.12$ [.068; .177], $p<.001)$ and the line 11 shows the indirect effect $a_{1} b_{2} c_{2}$ that is significant ( $\beta=.15$ [.111; .197], $p<.001$ ). The advantage of $\mathrm{R}$ is to provide the secondary indirect effects. The line 7 shows the secondary indirect effects $a_{1} b_{2}$ that is significant ( $\beta=.23$ [.172;.288], $p<.001$ ) and the line 10 shows the secondary indirect effects $b_{2} c_{2}$ that is significant $(\beta=.31$ [.242; .378], $p<.001)$.

\section{Practical example}

To provide the reader a better understanding of serial mediation analysis, a fictive example is presented. The data were generated with $\mathrm{R}$ like the previous method. In this example, we are interested in whether self-esteem and loneliness mediate the relationship between school victimization and depressive symptoms. In other words, we want to investigate whether low self-esteem and loneliness can explain why victimized adolescents are prone to depressive symptoms. Thus, the variables being studied are:

- Independent variable: Victimization (victimi)

- Dependent variable: Depressive symptoms (dep)

- Mediators: Low self-esteem (low_se) and Loneliness (lone).

An illustration of the model is provided in Figure 5, right panel, and the input for Mplus is provided in listing 4. To reproduce the analysis, the data file used is included in the supplementary documents of the manuscript.

\section{Results}

For the output of Mplus, to Appendix C, line 241 is the effect of victimization on low self-esteem (path $a_{1} ; \beta=.49$ [.419; .549]). Line 244 is the effect of victimization on loneliness (path $a_{2} ; \beta=.28$ [.181;.367]). Line 245 is the effect of low self-esteem on loneliness controlling for victimization (path $b_{2} ; \beta=.26$ [.170; .344]). Line 249 is the effect of low self-esteem on depression controlling for victimization (path $\left.c_{1} ; \beta=.35[.301 ; .405]\right)$. Line 250 is the effect of loneliness on depression controlling for victimization and low self-esteem (path $c_{2} ; \beta=.66$ [.617; .708]). The direct effect, the effect of victimization on depression controlling for the effects of low self-esteem and loneliness, is in lines 248 and 320 (path $d ; \beta=-.00$ [-.058; .0,58]). The total effect, the effect of victimization on depression, is in line 299 (path $e$; $\beta=.44[.355 ; .511])$ and the total indirect effect is in line 300 ( $\beta=.44[.372 ; .504])$. Indirect effect, $a_{1} c_{1}$, the effect of victimization on depression through low self-esteem is in line 305 ( $\beta=.17[.140 ; .210])$. Indirect effect $a_{2} c_{2}$, the effect of victimization on depression through loneliness is in line 310 ( $\beta=.18$ [.119; .249]). Finally, the indirect effect of serial mediation, $a_{1} b_{2} c_{2}$, the effect of victimization on depression through low self-esteem and loneliness is in line 316 ( $\beta=.08$ [.056; .115]).

\section{Presentation of the results}

The purpose of this manuscript has been to test the mediating role of low self-esteem and loneliness in the relationship between victimization and depression. To test our serial mediation model, we used Mplus software with bootstrapping of 5000 replications. The results reveal that victimization has an indirect effect on depression in the presence of low self-esteem and loneliness ( $\beta=.08$ [.056; .115]) with a 95\% confidence interval not including 0 . Specifically, Figure 5 , right panel, shows the standardized estimates found between the variables in the model. As observed, victimization has a significant and positive effect on low self-esteem ( $\beta=$ .49 [.419; .549]) and loneliness ( $\beta=.28$ [.181; .367]). In addition, self-esteem has a positive effect on loneliness when the effects of victimization are controlled $(\beta=.26$ [.170; .344]) as does loneliness on depression when victimization and self-esteem are controlled ( $\beta=.66[.617 ; .708])$ and self-esteem on depression when victimization is controlled ( $\beta=.35[.301 ; .405])$. The total effect, the effect of victimization on depression, is significantly positive $(\beta=.44$ [.355; .511]). Conversely, the effect of victimization on depression 
is non-significant when self-esteem and loneliness are controlled ( $\beta=-.00[-.058 ; .0,58])$. Finally, simple mediation effects can be observed. Indeed, the indirect effect between victimization and depression is significantly positive in the presence of the low self-esteem mediator $\left(a_{1} \times c_{1}=.17\right.$ [.140; $.210])$ and in the presence of the loneliness mediator $\left(a_{2} \times c_{2}=\right.$ .18 [.119; .249]) because 0 is not included in the 95\% interval.

\section{Conclusion}

Mediation analyses have been widely used in the human and social sciences. Many articles have dealt with the guidelines of simple mediation. However human complexity leads researchers to investigate more complicated models, such as adding multiple mediators. Thus, this manuscript provides a tutorial for any researcher or student who desires to perform serial mediation analysis with two mediators with PROCESS, Mplus and R. Through this tutorial, we hope to provide a better overview of serial mediation analysis and to encourage the reader to learn more about other types of mediations (e.g., parallel mediation, moderated mediation) or more complex models such as multilevel mediation models.

\section{Authors' note}

This project was partly subsided by a grant from the Fonds d'aide institutionnel à la recherche (FAIR) from the Social Sciences and Humanities Research Council.

\section{References}

Byrne, B. M. (2013). Structural equation modeling with Mplus. Chichester: Routledge.

Caron, P.-O. (2018). La modélisation par équations structurelles avec Mplus. Montréal: Presses de l'Université du Québec.

Caron, P.-O. (2019). A comparison of the type I error rates of three assessment methods for indirect effects. Journal of Statistical Computation and Simulation, 89(8), 13431356. doi:10.1080/00949655.2019.1577858

Caron, P.-O. (2021). pathanalysis. Retrieved from https:// github.com/quantmeth/pathanalysis

Caron, P.-O., \& Lemardelet, L. (2021). The variance sum law and its implications for modelling. The Quantitative Methods for Psychology, 17(2), 80-85. doi:10.20982/ tqmp.17.2.p080

Caron, P.-O., \& Valois, P. (2018). A computational description of simple mediation analysis. The Quantitative Methods for Psychology, 14(2), 147-158. doi:10.20982/ tqmp.14.2.p147

Cheung, G. W., \& Lau, R. S. (2008). Testing mediation and suppression effects of latent variables: Bootstrapping with structural equation models. Organiza- tional Research Methods, 11(2), 296-325. doi:10.1177/ 1094428107300343

Cole, D. A., \& Maxwell, S. E. (2003). Testing mediational models with longitudinal data: Questions and tips in the use of structural equation modeling. Journal of $A b$ normal Psychology, 112(4), 558-577. doi:10.1037/0021843X.112.4.558

Efron, B., \& Tibshriani, R. (1994). An introduction to the bootstrap. London: Chapman \& Hall.

Fairchild, A. J., \& McDaniel, H. L. (2017). Best (but oftforgotten) practices: Mediation analysis. The American Journal of Clinical Nutrition, 105(6), 1259-1271. doi:10.3945/ajcn.117.152546

Geiser, C. (2013). Data analysis with Mplus. New York: Guilford Press.

Gollob, H. F., \& Reichardt, C. S. (1987). Taking account of time lags in causal models. Child Development, 58(1), 80-92. doi:10.1111/j.1467-8624.1987.tb03492

Hayes, A. F. (2017). Introduction to mediation, moderation, and conditional process analysis : A regression-based approach (2nd ed.) New York: Guilford Oress.

IBM Corporation. (2020). IBM SPSS statistics for windows (Version 27.0). Amonk, NY: IBM Corporation.

Kane, L., \& Ashbaugh, A. R. (2017). Simple and parallel mediation: A tutorial exploring anxiety sensitivity, sensation seeking, and gender. The Quantitative Methods for Psychology, 13(3), 148-165. doi:10.20982/tqmp.13. 3.p148

Kelloway, E. K. (2015). Using Mplus for structural equation modeling. New York: Sage.

Lange, T., Hansen, K. W., Sørensen, R., \& Galatius, S. (2017). Applied mediation analyses: A review and tutorial. Epidemiology and Health, 39, 1-13. doi:10.4178/epih. e2017035

MacKinnon, D. P., Fairchild, A. J., \& Fritz, M. S. (2007). Mediation analysis. Annual Review of Psychology, 58(1), 593-614. doi:10 . 1146 / annurev . psych . 58 . 110405 . 085542

Muthén, L. K., \& Muthén, B. O. (2017). Mplus user's guide (8th ed.) Los Angeles: Muthén \& Muthén.

Özdil, S. O., \& Kutlu, O. M. (2019). Investigation of the mediator variable effect using BS, Sobel and bootstrap methods. International Journal of Progressive Education, 15(2), 30-43. doi:10.29329/ijpe.2019.189.3

Preacher, K. J. (2015). Advances in mediation analysis: A survey and synthesis of new developments. Annual Review of Psychology, 66, 825-852. doi:10.1146/ annurev-psych-010814-015258

R Core Team. (2021). R: A language and environment for statistical computing. In R Foundation for Statistical Computing. Retrieved from http://www.Rproject.org/ 
Team, R. (2020). RStudio: Integrated Development Environment for R. Retrieved from http://www.rstudio.com/ Tingley, D., Yamamoto, T., Hirose, K., Keele, L., \& Imai, K. (2014). Mediation: R package for causal mediation analysis. Journal of Statistical Software, 59(5), 1-38. Retrieved from http://www.jstatsoft.org/v59/i05/
Tofighi, D., \& Mackinnon, D. P. (2011). Rmediation: An r package for mediation analysis confidence intervals. Behavior Research Methods, 43(3), 692-700. doi:10 . 3758/s13428-011-0076-x

Wang, J., \& Wang, X. (2020). Structural equation modeling with Mplus: Methods and applications (2nd ed.) Hoboken, NJ: John Wiley \& Sons.

\section{Listing 1 a Generate data with $\mathbf{R}$}

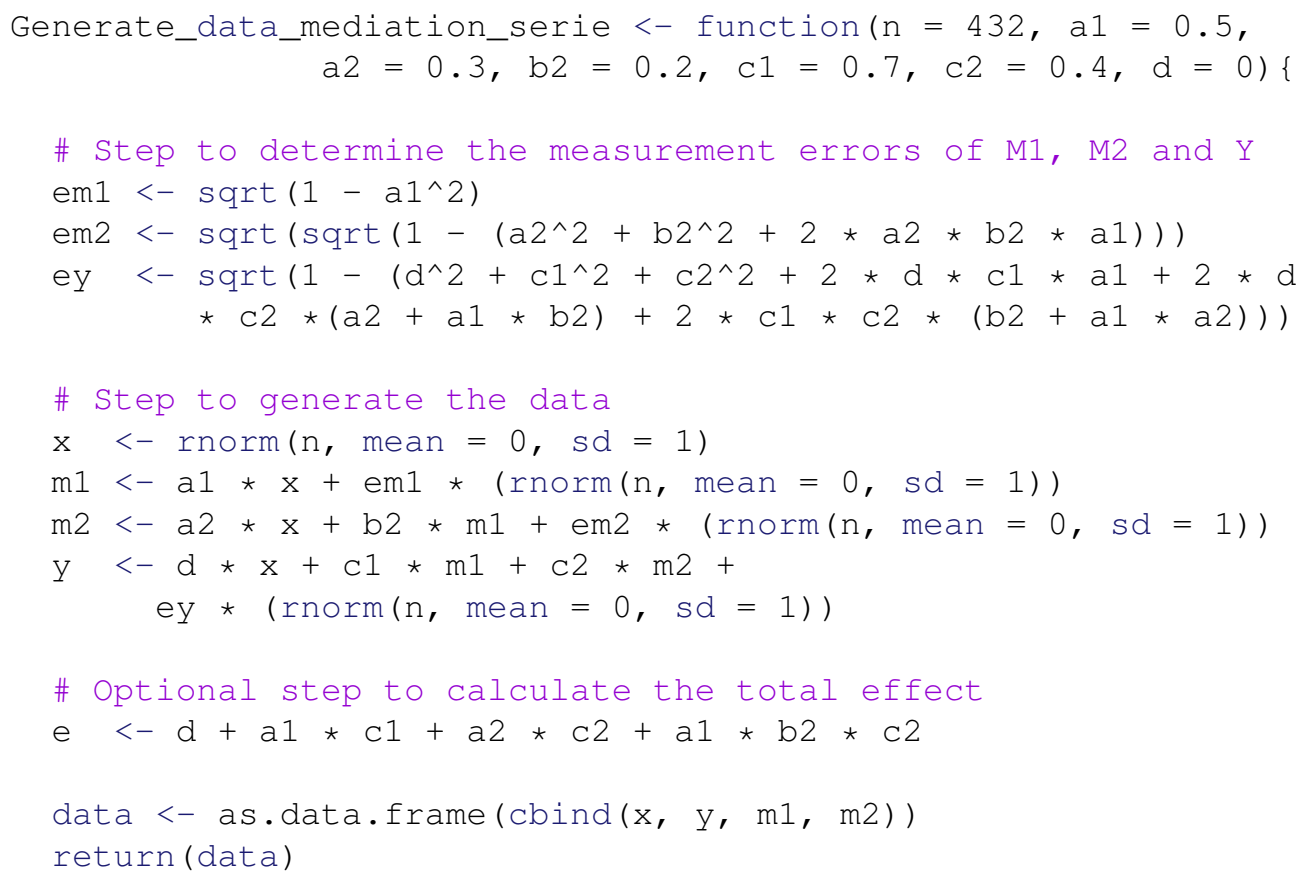

\section{Listing 2 The Mplus input file}

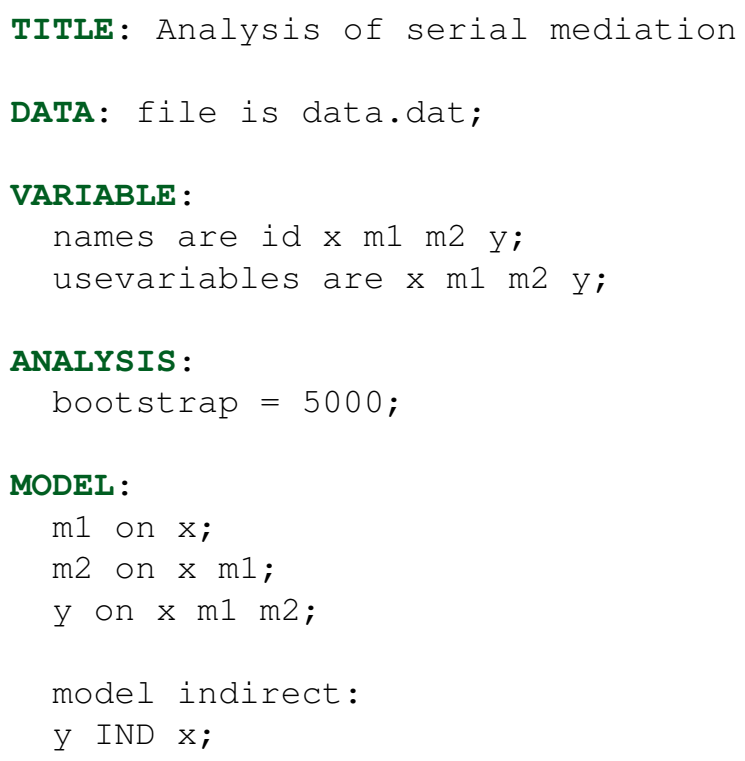


20 OUTPUT: stdyx cinterval (bcbootstrap);

\section{Listing 3 m Illustration in $\mathbf{R}$ of the serial mediation with two mediators.}

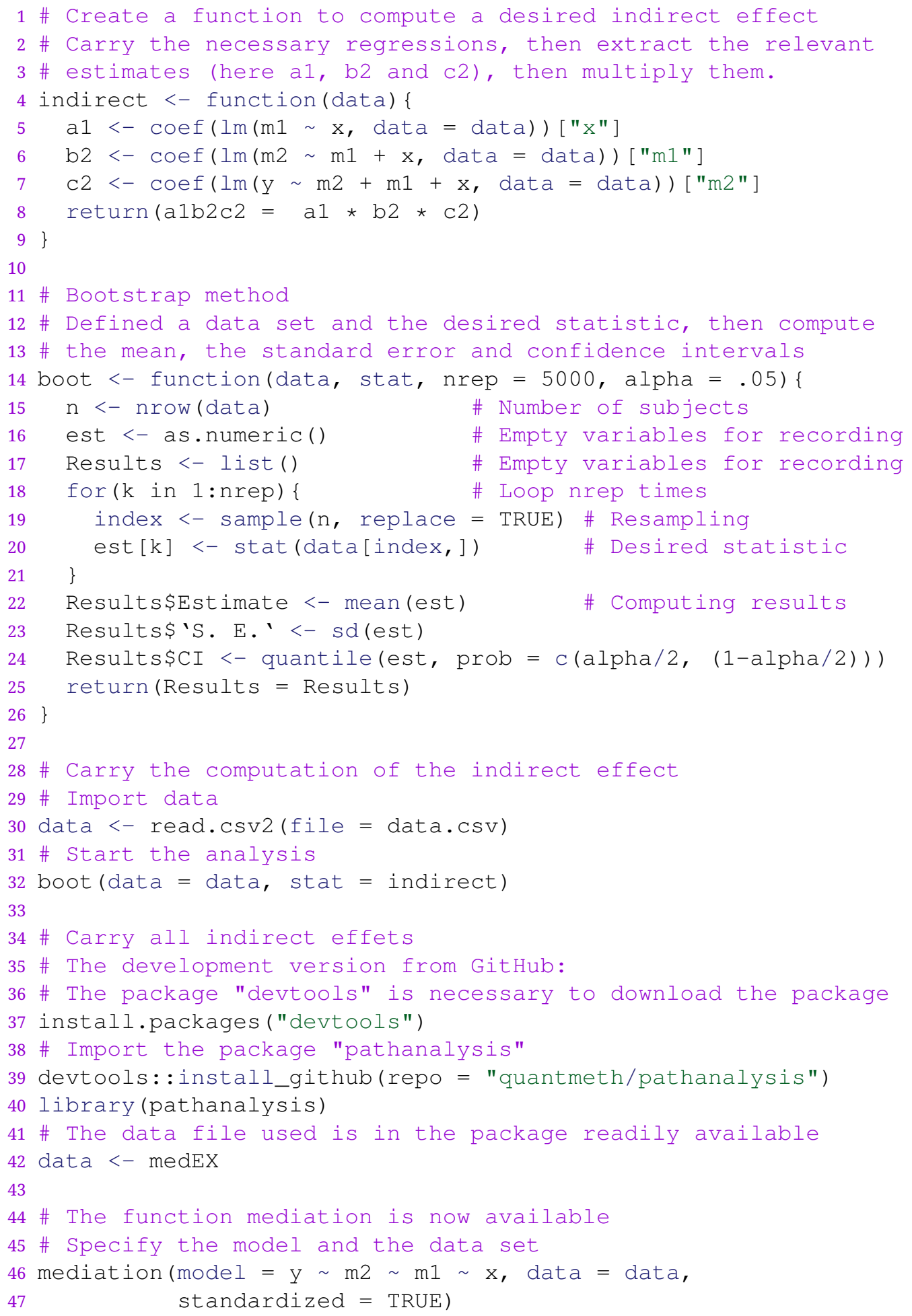




\section{Listing 4 - The Mplus input file for the application of serial mediation}

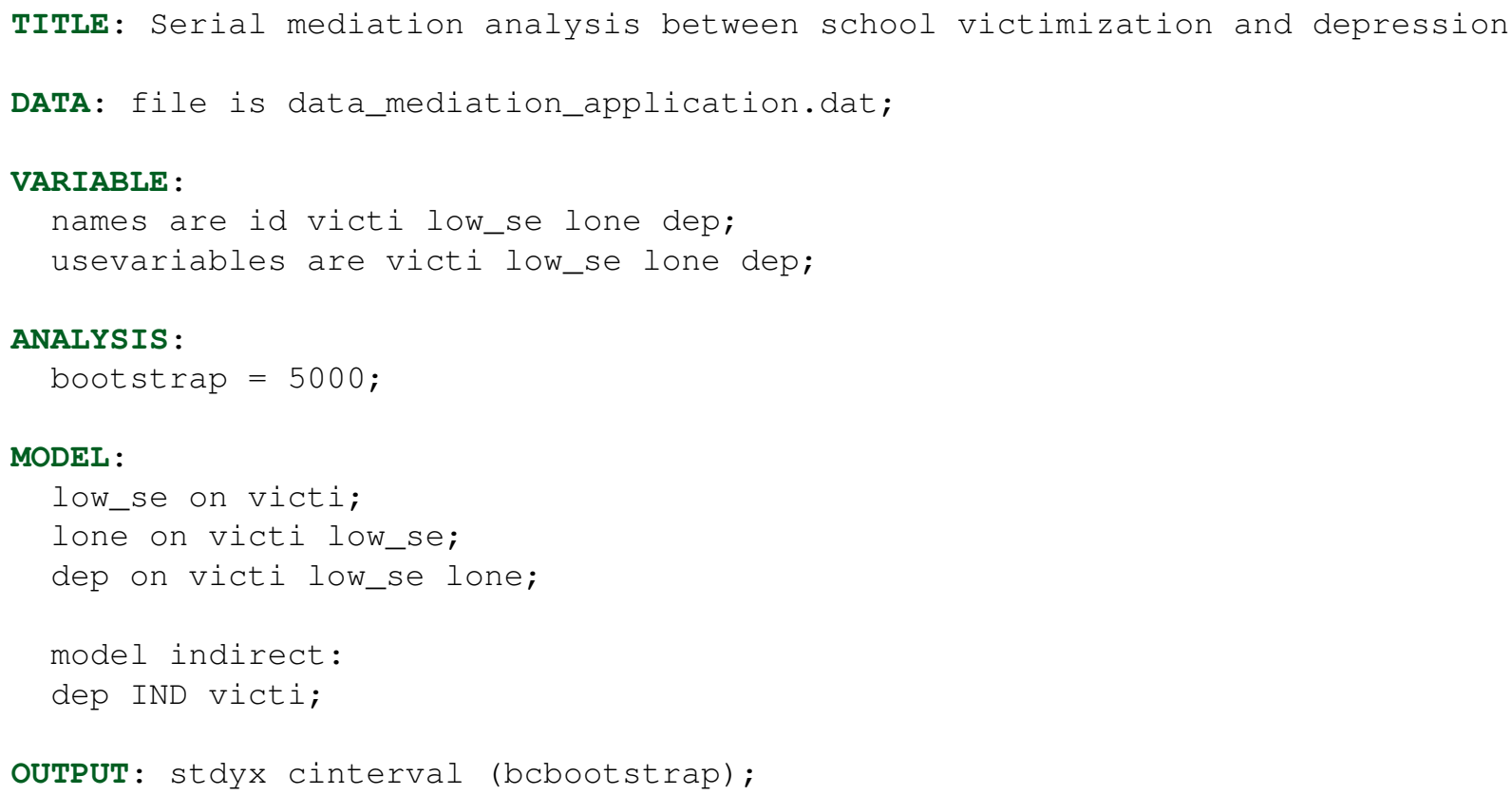

\section{Appendix A $\square$ The output file from PROCESS}

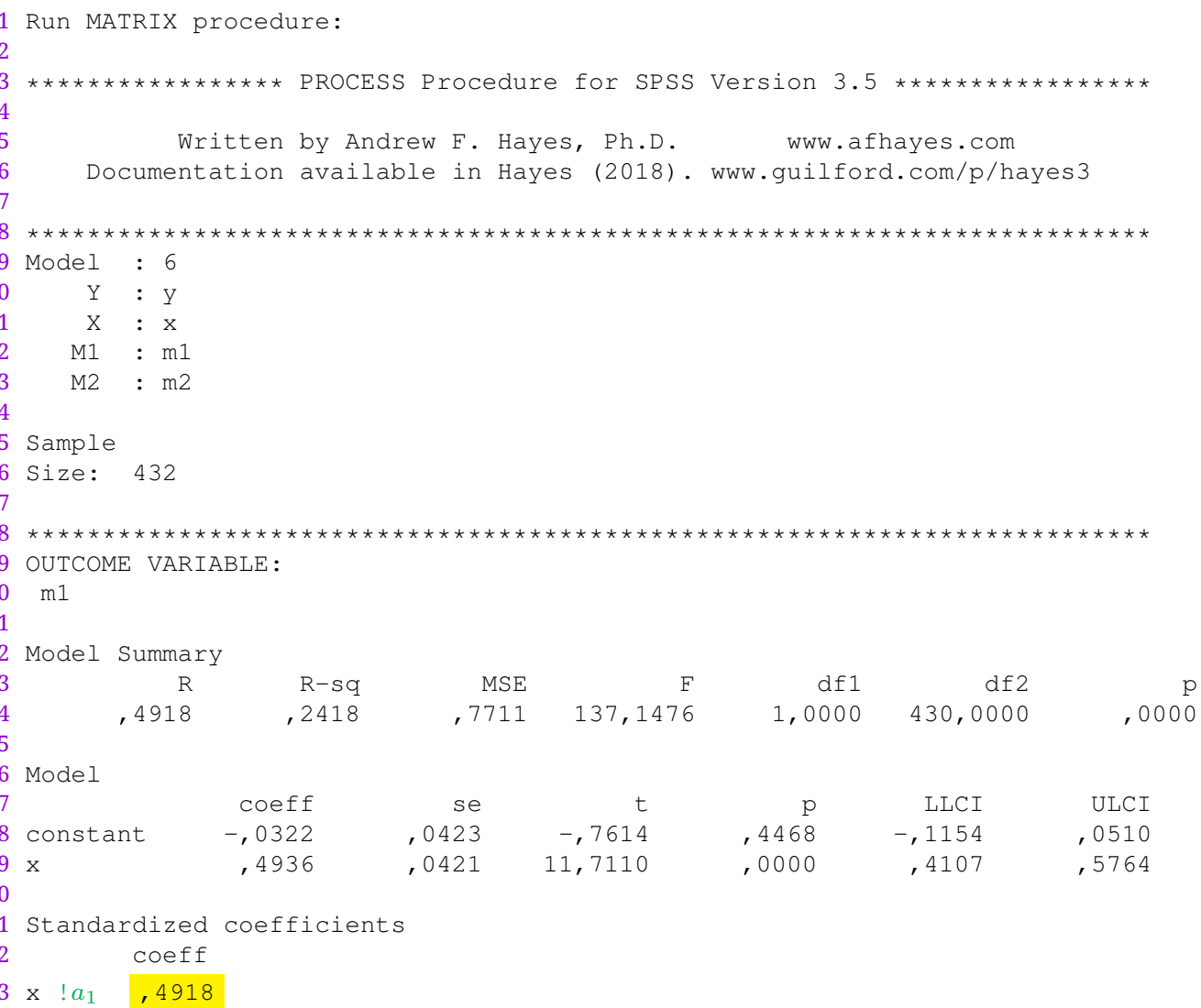




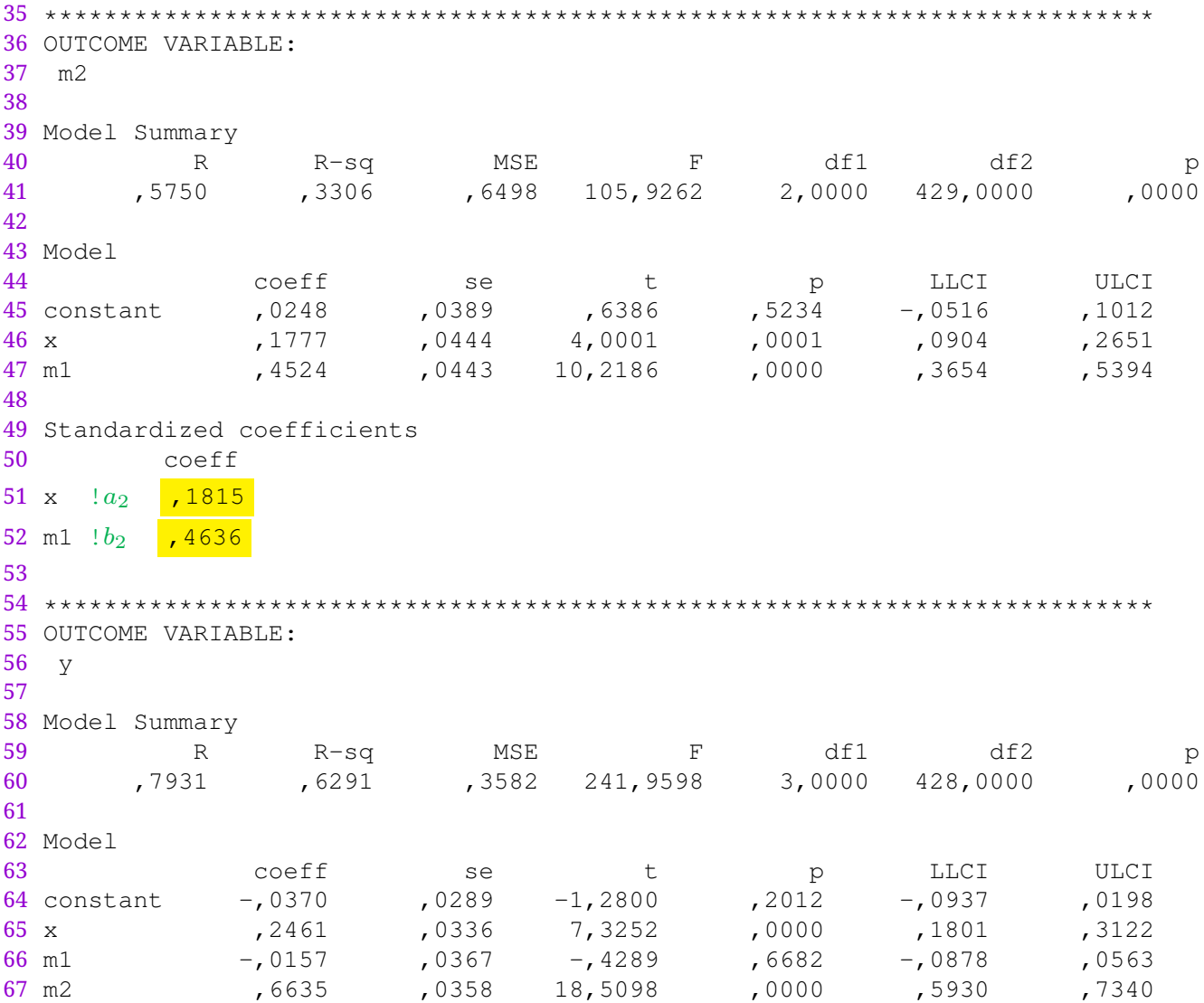




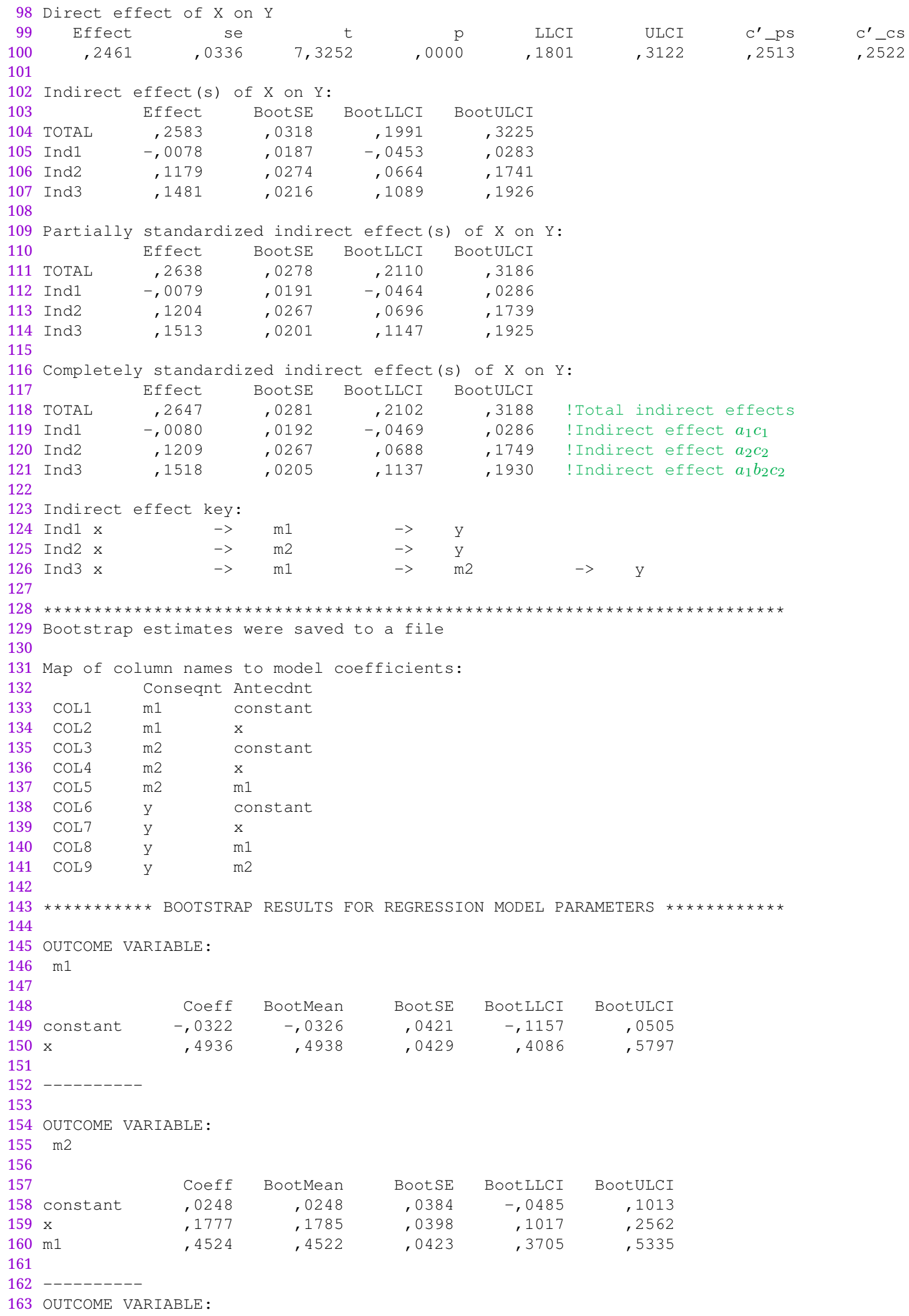


Y

165

166

167 constant

$168 \mathrm{x}$

$169 \mathrm{~m} 1$

$170 \mathrm{~m} 2$

171

172

173

174 Level of confidence for all confidence intervals in output:

17595,0000

176

177 Number of bootstrap samples for percentile bootstrap confidence intervals:

$178 \quad 5000$

179

180

\section{Appendix B $\square$ The output file from Mplus}

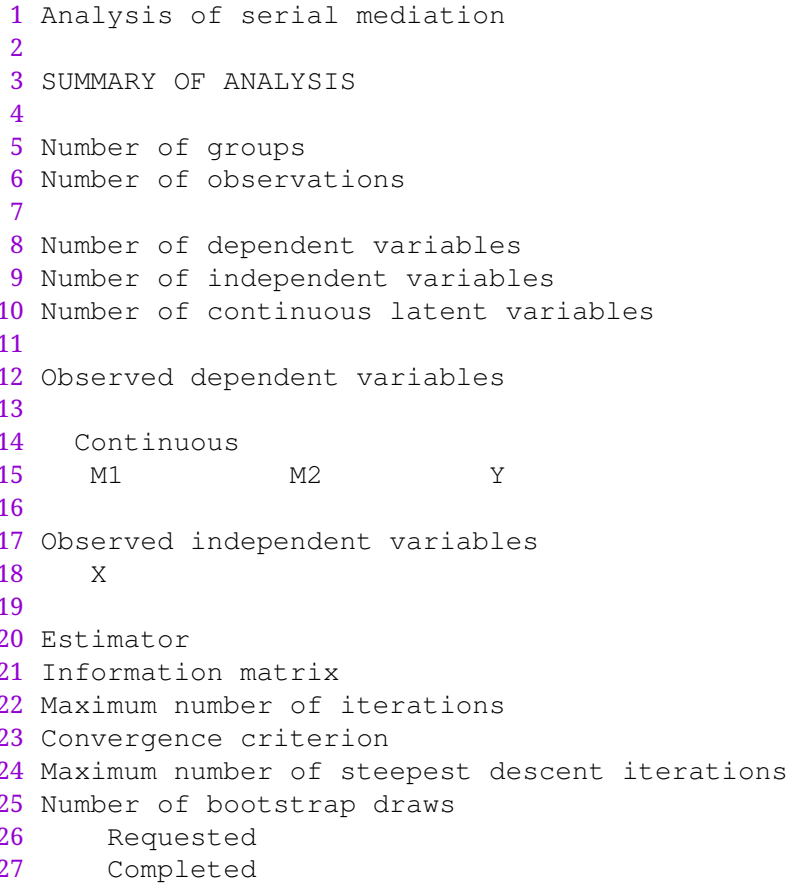




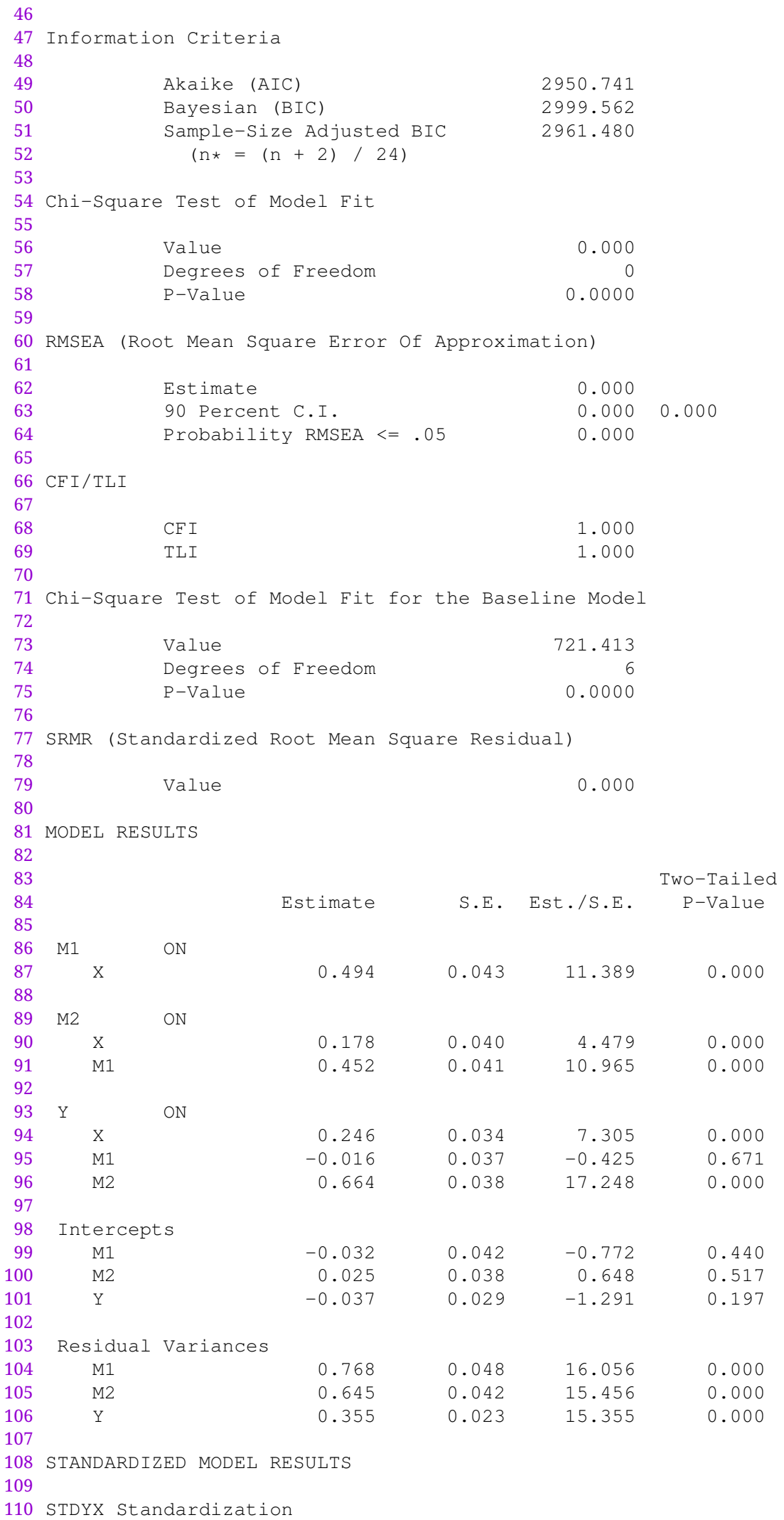




\begin{tabular}{|c|c|c|c|c|c|c|}
\hline 112 & & & & & Two-Tailed & \\
\hline 113 & & Estimate & S.E. & Est./S.E. & P-Value & \\
\hline 114 & & & & & & \\
\hline 115 & M1 & & & & & \\
\hline 116 & $\mathrm{x}$ & 0.492 & 0.037 & 13.447 & 0.000 & \\
\hline 117 & & & & & & \\
\hline 118 & ON & & & & & \\
\hline 119 & X & 0.182 & 0.039 & 4.605 & 0.000 & \\
\hline 120 & M1 & 0.464 & 0.040 & 11.680 & 0.000 & \\
\hline 121 & & & & & & \\
\hline 122 & ON & & & & & \\
\hline 123 & $\mathrm{x}$ & 0.252 & 0.035 & 7.209 & 0.000 & \\
\hline 124 & M1 & -0.016 & 0.038 & -0.426 & 0.670 & \\
\hline 125 & M2 & 0.666 & 0.031 & 21.191 & 0.000 & \\
\hline 126 & & & & & & \\
\hline 127 & Intercepts & & & & & \\
\hline 128 & M1 & -0.032 & 0.042 & -0.770 & 0.442 & \\
\hline 129 & M2 & 0.025 & 0.039 & 0.645 & 0.519 & \\
\hline 130 & $\mathrm{Y}$ & -0.038 & 0.029 & -1.290 & 0.197 & \\
\hline 131 & & & & & & \\
\hline 132 & Residual Variances & & & & & \\
\hline 133 & M1 & 0.758 & 0.036 & 21.220 & 0.000 & \\
\hline 134 & M2 & 0.669 & 0.036 & 18.462 & 0.000 & \\
\hline 135 & $\mathrm{Y}$ & 0.371 & 0.027 & 13.515 & 0.000 & \\
\hline 136 & & & & & & \\
\hline 137 & R-SQUARE & & & & & \\
\hline 138 & & & & & & \\
\hline 139 & Observed & & & & Two-Tailed & \\
\hline 140 & Variable & Estimate & S.E. & Est./S.E. & P-Value & \\
\hline 141 & & & & & & \\
\hline 142 & M1 & 0.242 & 0.036 & 6.768 & 0.000 & \\
\hline 143 & M2 & 0.331 & 0.036 & 9.117 & 0.000 & \\
\hline 144 & $\mathrm{Y}$ & 0.629 & 0.027 & 22.922 & 0.000 & \\
\hline 145 & & & & & & \\
\hline $\begin{array}{l}146 \\
147\end{array}$ & TOTAL, TOTAL INDIREC & $C T, \quad S P E C I F I C$ & IND IRECT, & AND DIRECT & EFFECTS & \\
\hline 148 & & & & & Two-Tailed & \\
\hline 149 & & Estimate & S.E. & Est./S.E. & P-Value & \\
\hline 150 & & & & & & \\
\hline 151 & Effects from $X$ to $Y$ & & & & & \\
\hline 152 & & & & & & \\
\hline 153 & Total & 0.504 & 0.040 & 12.581 & 0.000 & \\
\hline 154 & Total indirect & 0.258 & 0.032 & 8.043 & 0.000 & \\
\hline 155 & & & & & & \\
\hline 156 & Specific indirect & 1 & & & & \\
\hline 157 & $\mathrm{Y}$ & & & & & \\
\hline 158 & M1 & & & & & \\
\hline 159 & $\mathrm{x}$ & -0.008 & 0.018 & -0.424 & 0.672 & \\
\hline 160 & & & & & & \\
\hline 161 & Specific indirect & 2 & & & & \\
\hline 162 & $\mathrm{Y}$ & & & & & \\
\hline 163 & M2 & & & & & \\
\hline 164 & $\mathrm{x}$ & 0.118 & 0.027 & 4.307 & 0.000 & \\
\hline 165 & & & & & & \\
\hline 166 & Specific indirect & 3 & & & & \\
\hline 167 & $\mathrm{Y}$ & & & & & \\
\hline 168 & M2 & & & & & \\
\hline 169 & M1 & & & & & \\
\hline 170 & $\mathrm{x}$ & 0.148 & 0.021 & 6.979 & 0.000 & \\
\hline 171 & & & & & & \\
\hline 172 & Direct & & & & & \\
\hline 173 & $\mathrm{Y}$ & & & & & \\
\hline 174 & $\mathrm{x}$ & 0.246 & 0.034 & 7.305 & 0.000 & \\
\hline 175 & & & & & & \\
\hline $\begin{array}{l}176 \\
177\end{array}$ & STANDARDIZED TOTAL, & TOTAL INDIRE & ECT, SPECIE & FIC INDIRECT & T, AND DIRECT & EFFECTS \\
\hline
\end{tabular}




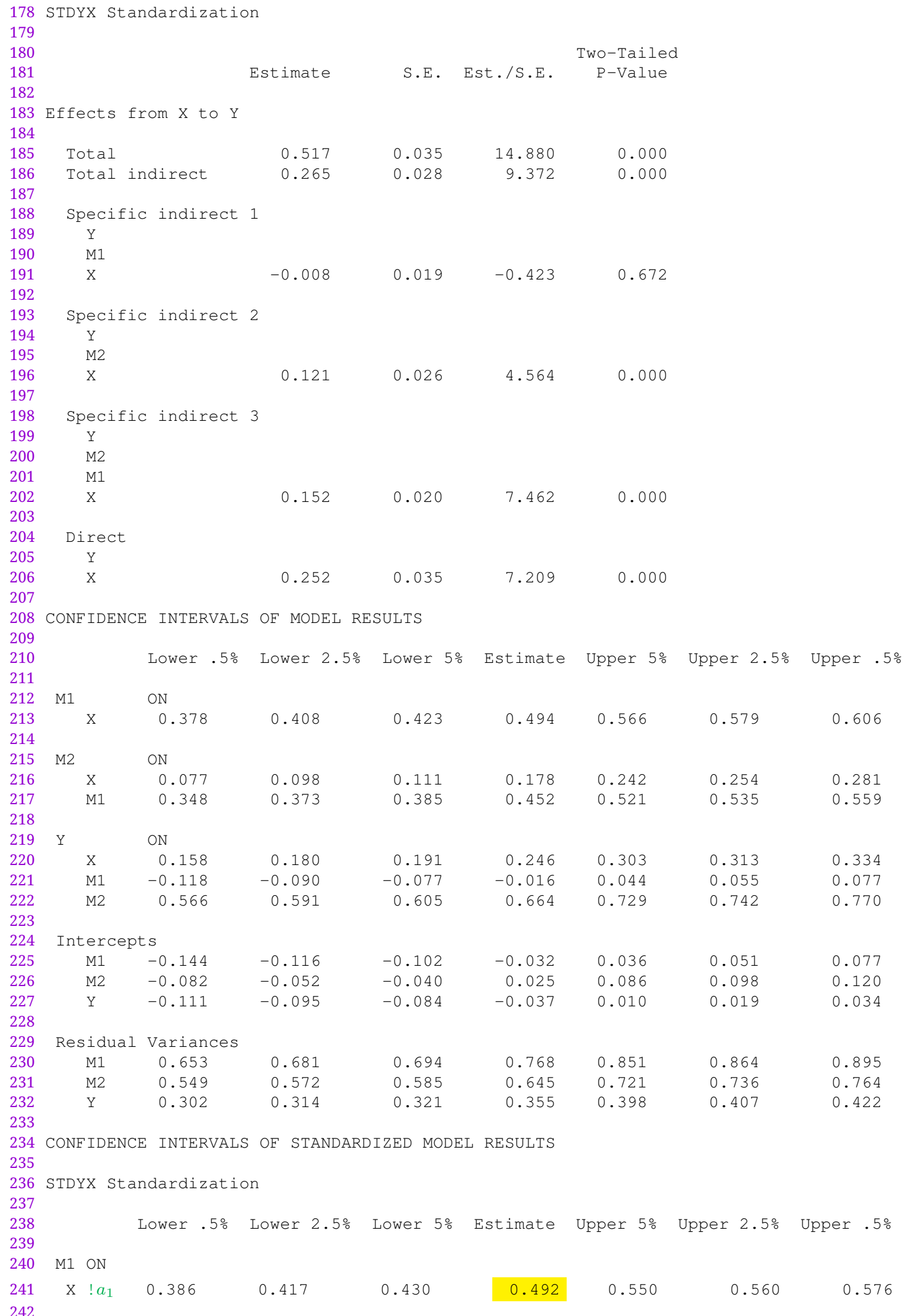




\begin{tabular}{|c|c|c|c|c|c|c|c|}
\hline $\mathrm{X} \quad ! a_{2}$ & 0.080 & 0.101 & 0.115 & 0.182 & 0.245 & 0.256 & 0.281 \\
\hline M1 $! b_{2}$ & 0.358 & 0.386 & 0.398 & 0.464 & 0.528 & 0.542 & 0.565 \\
\hline \multicolumn{8}{|l|}{$\mathrm{Y} O \mathrm{~N}$} \\
\hline $\mathrm{x} \quad ! d$ & 0.157 & 0.183 & 0.194 & 0.252 & 0.309 & 0.320 & 0.343 \\
\hline M1 $! c_{1}$ & -0.119 & -0.092 & -0.079 & -0.016 & 0.046 & 0.056 & 0.079 \\
\hline $\mathrm{M} 2 \quad ! c_{2}$ & 0.581 & 0.604 & 0.615 & 0.666 & 0.717 & 0.727 & 0.744 \\
\hline \multicolumn{8}{|c|}{ Intercepts } \\
\hline M1 & -0.145 & -0.116 & -0.102 & -0.032 & 0.035 & 0.051 & 0.077 \\
\hline M2 & -0.086 & -0.054 & -0.041 & 0.025 & 0.088 & 0.100 & 0.123 \\
\hline Y & -0.114 & -0.096 & -0.086 & -0.038 & 0.010 & 0.020 & 0.036 \\
\hline \multicolumn{8}{|c|}{ Residual Variances } \\
\hline M1 & 0.667 & 0.685 & 0.698 & 0.758 & 0.815 & 0.826 & 0.851 \\
\hline M2 & 0.578 & 0.600 & 0.612 & 0.669 & 0.731 & 0.743 & 0.764 \\
\hline $\mathrm{Y}$ & 0.307 & 0.321 & 0.329 & 0.371 & 0.421 & 0.431 & 0.449 \\
\hline
\end{tabular}

CONFIDENCE INTERVALS OF TOTAL, TOTAL INDIRECT, SPECIFIC INDIRECT, AND DIRECT EFFECTS

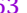




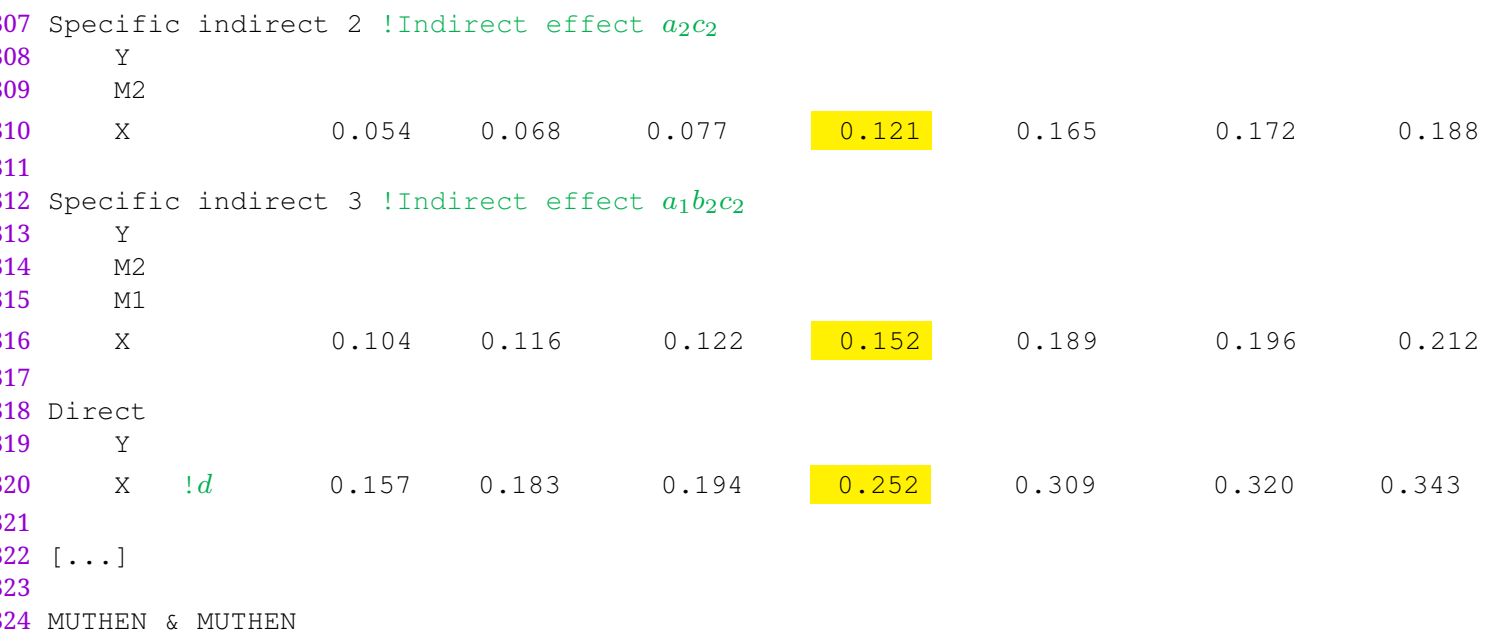

$[\ldots]$

24 MUTHEN \& MUTHEN

$325[\ldots]$

\section{Appendix $\mathrm{C} \backsim$ The Mplus output file for the application of serial mediation}

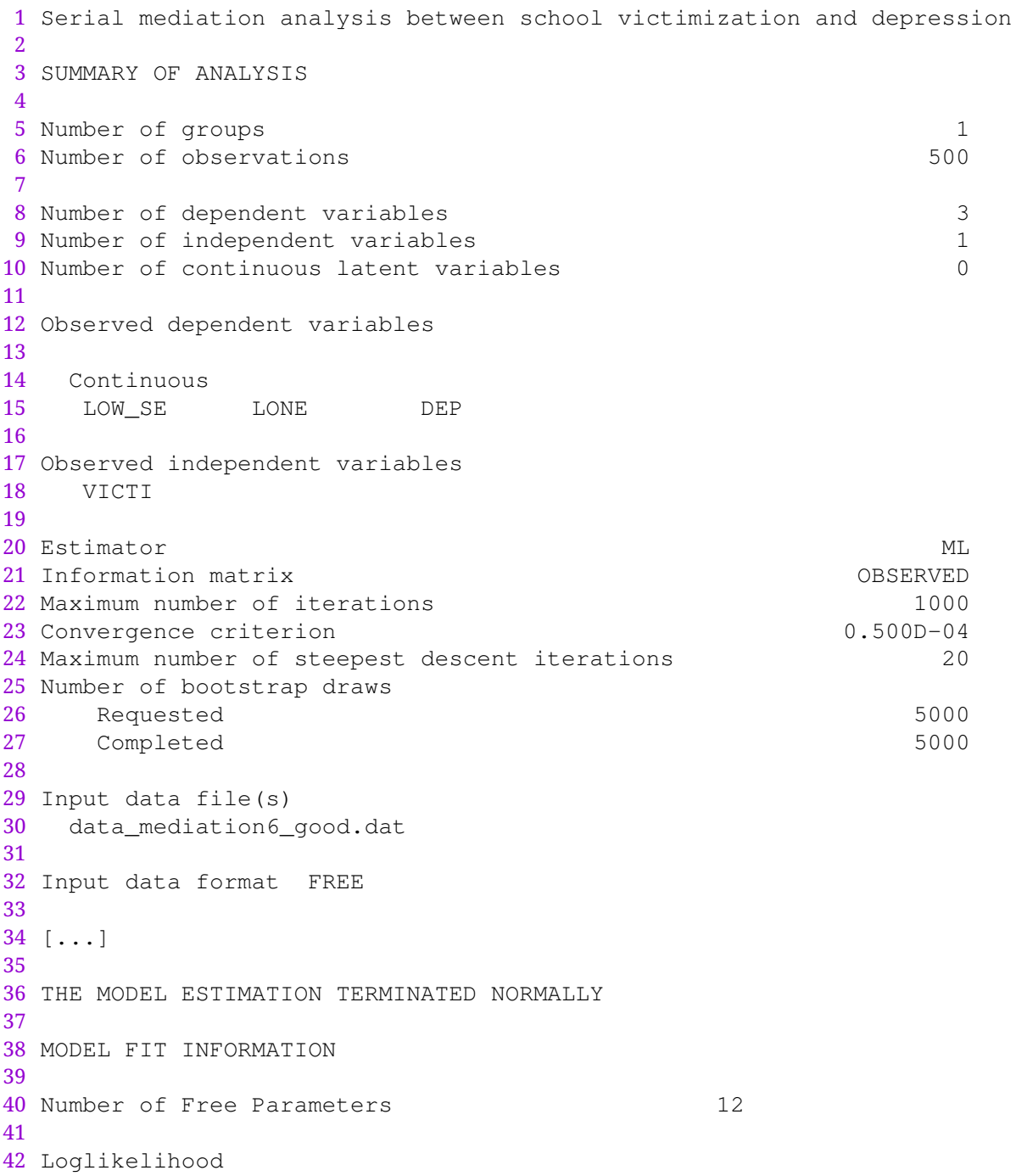




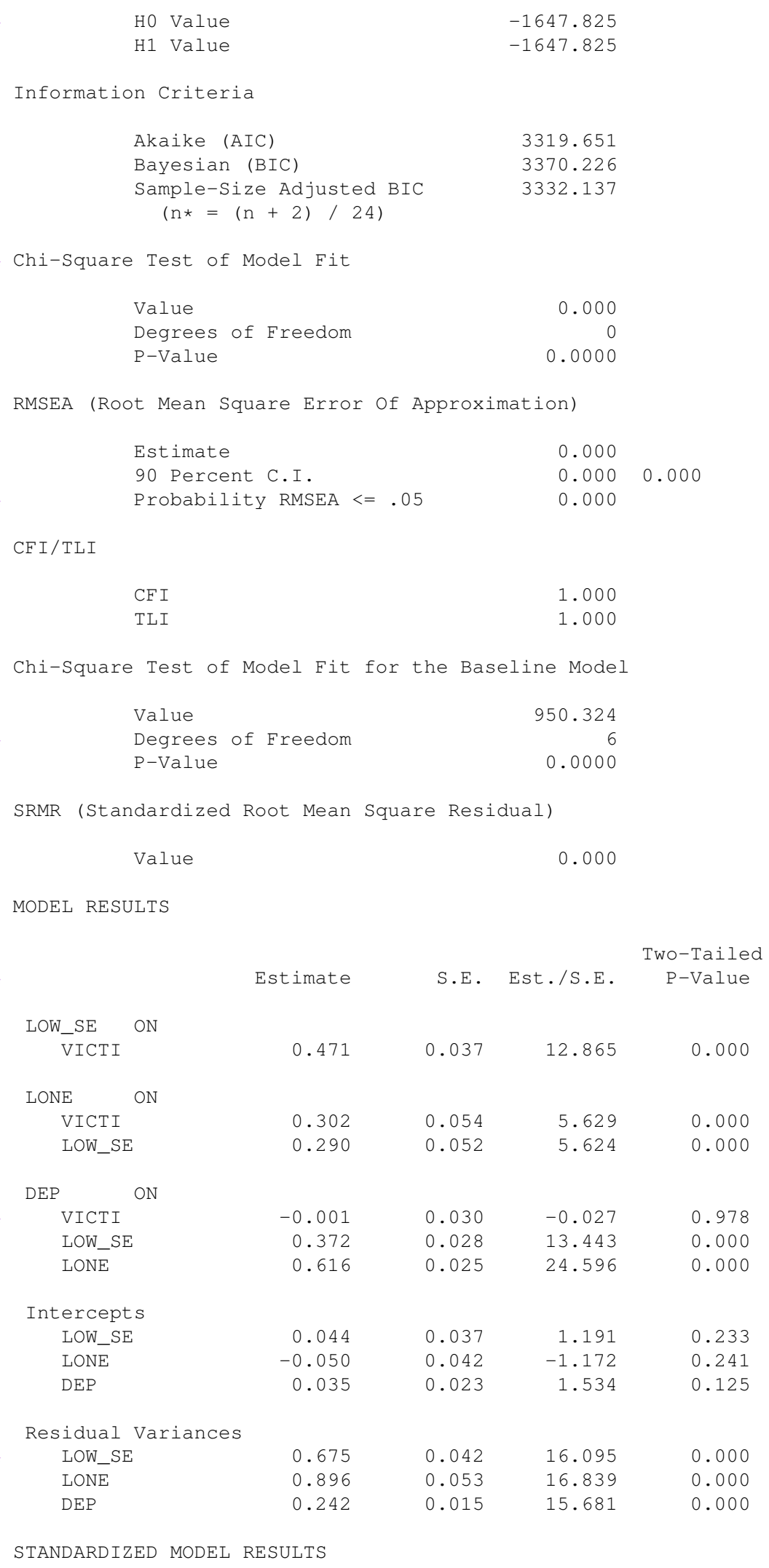


109

110 STDYX Standardization

111

112

113

114

115

116

117

118

119

120

121

122

123

124

125

126

127

128

129

130

131

132

133

134

135

136

137

138

139

140

141

142

143

144

145

146

147

148

149

150

151

152

154

155

156

157

158

159

160

161

162

163

164

165

166

167

168

169

170

171

172

173

174

\begin{tabular}{|c|c|c|c|c|}
\hline & Estimate & S.E. & Est./S.E. & $\begin{array}{c}\text { Two-Tailed } \\
\text { P-Value }\end{array}$ \\
\hline \multicolumn{5}{|l|}{ LOW_SE ON } \\
\hline VICTI & 0.488 & 0.033 & 14.608 & 0.000 \\
\hline LONE & & & & \\
\hline VICTI & 0.276 & 0.048 & 5.796 & 0.000 \\
\hline LOW_SE & 0.256 & 0.045 & 5.741 & 0.000 \\
\hline $\mathrm{DEP}$ & & & & \\
\hline VICTI & -0.001 & 0.029 & -0.027 & 0.978 \\
\hline LOW_SE & 0.355 & 0.026 & 13.450 & 0.000 \\
\hline LONE & 0.665 & 0.023 & 28.547 & 0.000 \\
\hline \multicolumn{5}{|l|}{ Intercepts } \\
\hline LOW_SE & 0.046 & 0.039 & 1.190 & 0.234 \\
\hline LONE & -0.047 & 0.040 & -1.162 & 0.245 \\
\hline $\mathrm{DEP}$ & 0.036 & 0.023 & 1.537 & 0.124 \\
\hline \multicolumn{5}{|c|}{ Residual Variances } \\
\hline LOW_SE & 0.762 & 0.032 & 23.533 & 0.000 \\
\hline LONE & 0.789 & 0.033 & 24.089 & 0.000 \\
\hline $\mathrm{DEP}$ & 0.248 & 0.020 & 12.658 & 0.000 \\
\hline \multicolumn{5}{|l|}{ R-SQUARE } \\
\hline \multicolumn{2}{|l|}{ Observed } & & & Two-Tailed \\
\hline Variable & Estimate & S.E. & Est./S.E. & P-Value \\
\hline LOW_SE & 0.238 & 0.032 & 7.343 & 0.000 \\
\hline LONE & 0.211 & 0.033 & 6.431 & 0.000 \\
\hline DEP & 0.752 & 0.020 & 38.287 & 0.000 \\
\hline
\end{tabular}

OTAL, TOTAL INDIRECT, SPECIFIC INDIRECT, AND DIRECT EFFECTS

\begin{tabular}{|c|c|c|c|c|}
\hline & Estimate & S.E. & Est./S.E. & $\begin{array}{c}\text { Two-Tailed } \\
\text { P-Value }\end{array}$ \\
\hline ffects from VICTI & to DEP & & & \\
\hline Total & 0.444 & 0.042 & 10.612 & 0.000 \\
\hline Total indirect & 0.445 & 0.038 & 11.810 & 0.000 \\
\hline $\begin{array}{l}\text { Specific indirect } \\
\text { DEP } \\
\text { LOW_SE }\end{array}$ & 1 & & & \\
\hline VICTI & 0.175 & 0.019 & 9.382 & 0.000 \\
\hline $\begin{array}{l}\text { Specific indirect } \\
\text { DEP } \\
\text { LONE }\end{array}$ & 2 & & & \\
\hline VICTI & 0.186 & 0.034 & 5.538 & 0.000 \\
\hline $\begin{array}{l}\text { Specific indirect } \\
\text { DEP } \\
\text { LONE } \\
\text { LOW_SE }\end{array}$ & 3 & & & \\
\hline VICTI & 0.084 & 0.017 & 5.093 & 0.000 \\
\hline $\begin{array}{c}\text { Direct } \\
\text { DEP }\end{array}$ & & & & \\
\hline VICTI & -0.001 & 0.030 & -0.027 & 0.978 \\
\hline
\end{tabular}




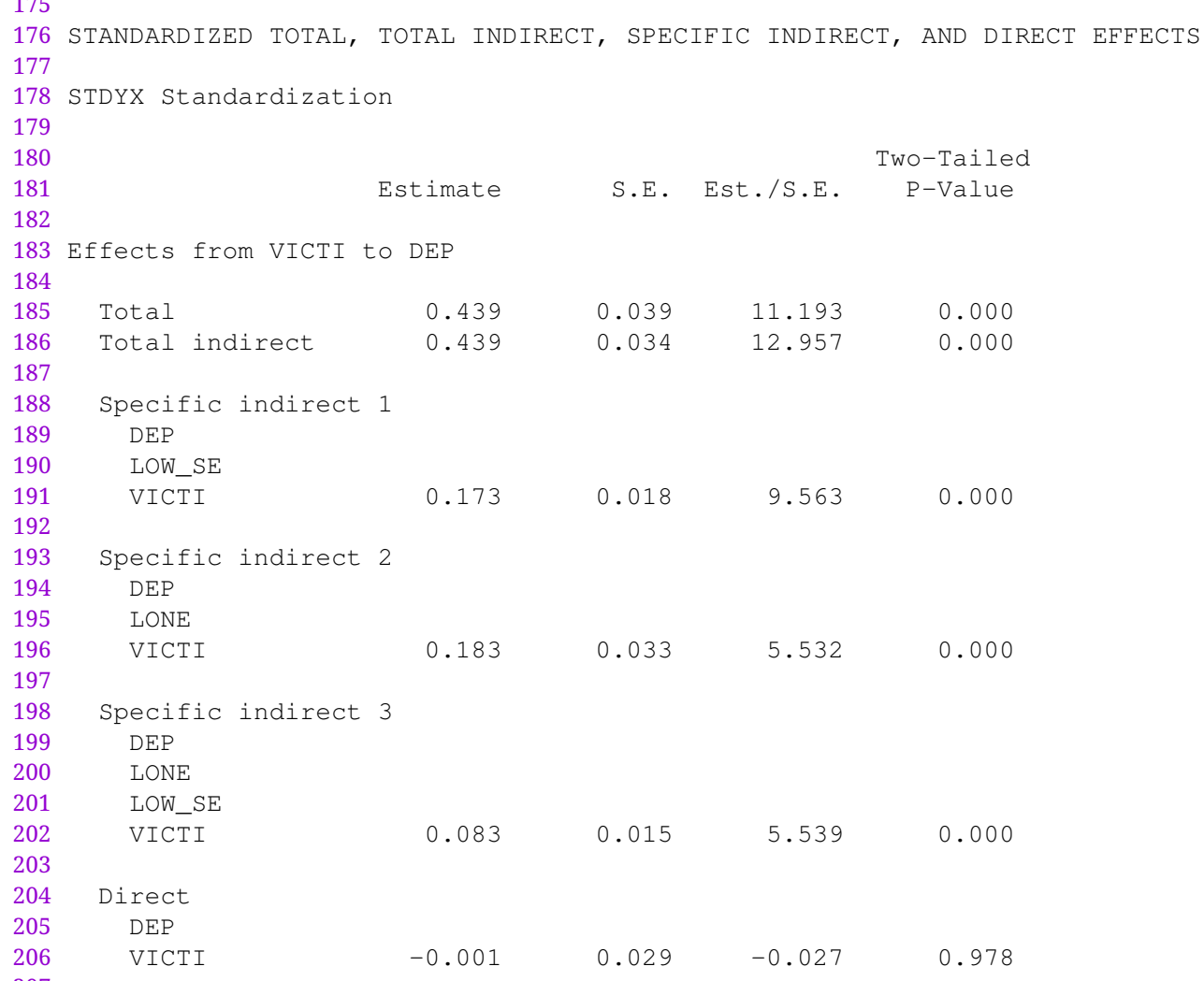




\begin{tabular}{|c|c|c|c|c|c|c|c|c|}
\hline VICTI & $! a_{1}$ & 0.398 & 0.419 & 0.430 & 0.488 & 0.540 & 0.549 & 0.569 \\
\hline LONE & $\mathrm{ON}$ & & & & & & & \\
\hline VICTI & $! a_{2}$ & 0.149 & 0.181 & 0.196 & 0.276 & 0.352 & 0.367 & 0.397 \\
\hline LOW_SE & $! b_{2}$ & 0.146 & 0.170 & 0.184 & 0.256 & 0.330 & 0.344 & 0.370 \\
\hline $\mathrm{DEP}$ & $\mathrm{ON}$ & & & & & & & \\
\hline VICTI & $! d$ & -0.076 & -0.058 & -0.049 & -0.001 & 0.047 & 0.058 & 0.076 \\
\hline LOW_SE & $! c_{1}$ & 0.285 & 0.301 & 0.310 & 0.355 & 0.397 & 0.405 & 0.422 \\
\hline LONE & $! c_{2}$ & 0.601 & 0.617 & 0.625 & 0.665 & 0.702 & 0.708 & 0.722 \\
\hline \multicolumn{9}{|c|}{ Intercepts } \\
\hline LOW_SE & $=-0.0$ & & -0.032 & -0.020 & 0.046 & 0.108 & 0.119 & 0.143 \\
\hline LONE & -0.1 & 146 & -0.124 & -0.112 & -0.047 & 0.021 & 0.034 & 0.056 \\
\hline DEP & -0.0 & 025 & -0.010 & -0.003 & 0.036 & 0.073 & 0.081 & 0.096 \\
\hline \multicolumn{9}{|c|}{ Residual Variances } \\
\hline LOW_SE & 0.6 & 676 & 0.699 & 0.709 & 0.762 & 0.815 & 0.825 & 0.842 \\
\hline LONE & 0.7 & 706 & 0.727 & 0.737 & 0.789 & 0.845 & 0.854 & 0.873 \\
\hline DEP & 0.2 & 202 & 0.213 & 0.218 & 0.248 & 0.283 & 0.290 & 0.303 \\
\hline
\end{tabular}

CONFIDENCE INTERVALS OF TOTAL, TOTAL INDIRECT, SPECIFIC INDIRECT, AND DIRECT EFFECTS 264 265 266 267

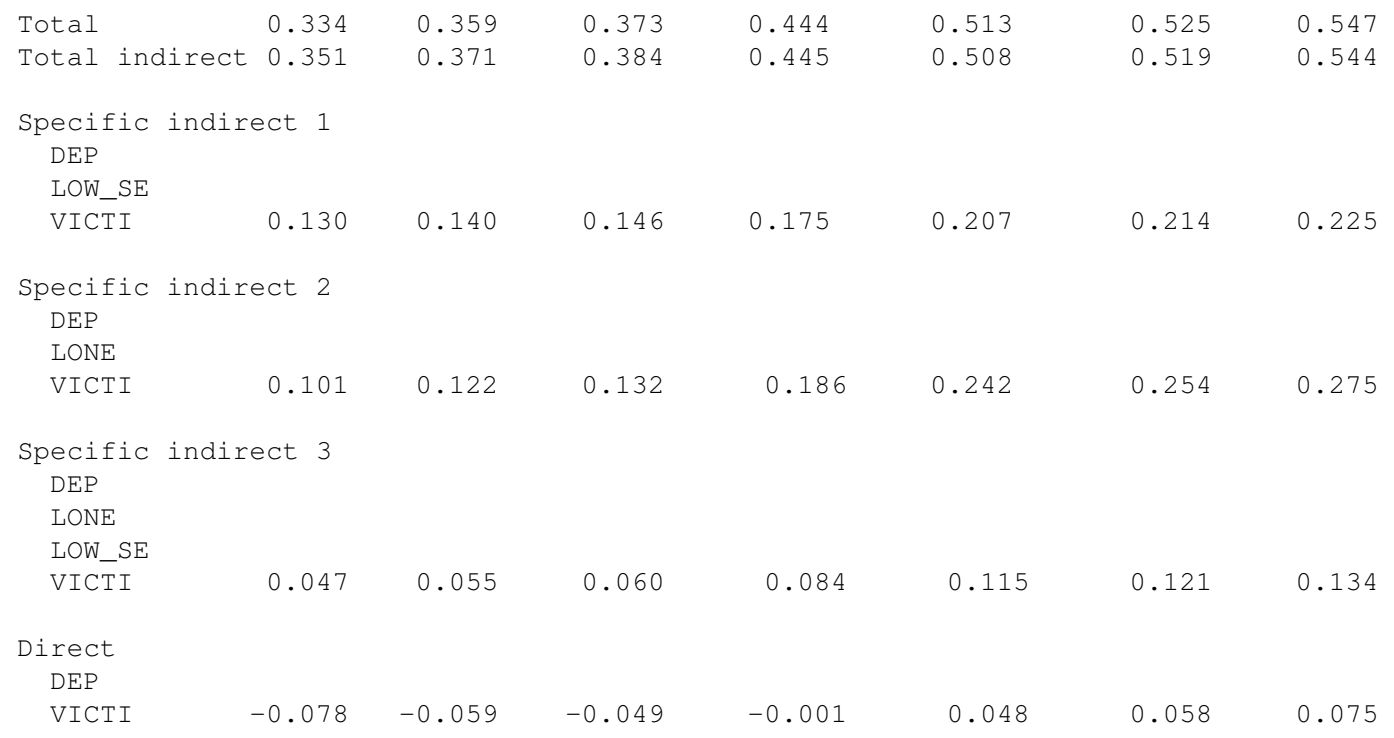




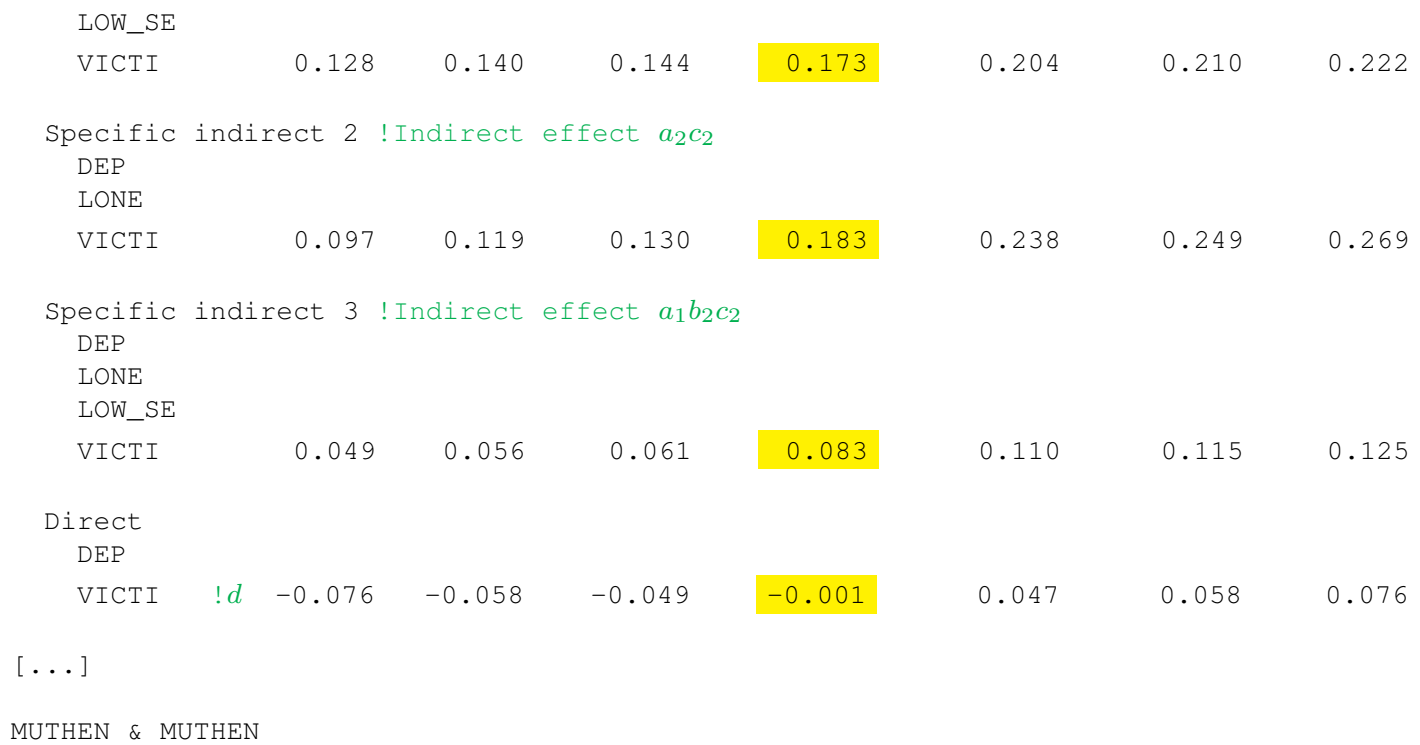

\section{Open practices}

(1) The Open Data badge was earned because the data of the experiment(s) are available on the journal's web site. - The Open Material badge was earned because supplementary material(s) are available on the journal's web site.

\section{Citation}

Lemardelet, L., \& Caron, P.-O. (2022). Illustrations of serial mediation using PROCESS, Mplus and R. The Quantitative Methods for Psychology, 18(1), 66-90. doi:10.20982/tqmp.18.1.p066

Copyright @ 2022, Lemardelet and Caron. This is an open-access article distributed under the terms of the Creative Commons Attribution License (CC BY). The use, distribution or reproduction in other forums is permitted, provided the original author(s) or licensor are credited and that the original publication in this journal is cited, in accordance with accepted academic practice. No use, distribution or reproduction is permitted which does not comply with these terms.

Received: 16/08/2021 Accepted: 31/01/2022 